\title{
Asiatic Acid Prevents Cognitive Deficits by Inhibiting Calpain Activation and Preserving Synaptic and Mitochondrial Function in Rats with Kainic Acid-Induced Seizure
}

\author{
Cheng-Wei Lu ${ }^{1,2,+}$, Tzu-Yu Lin ${ }^{1,2,+}$, Tai-Long Pan ${ }^{3,4}{ }^{\mathbb{D}}$, Pei-Wen Wang ${ }^{5}$, Kuan-Ming Chiu ${ }^{6,7,8}$, Ming-Yi Lee ${ }^{6}$ \\ and Su-Jane Wang $9,10, *$ (D)
}

check for

updates

Citation: Lu, C.-W.; Lin, T.-Y.; Pan, T.-L.; Wang, P.-W.; Chiu, K.-M.; Lee, M.-Y.; Wang, S.-J. Asiatic Acid Prevents Cognitive Deficits by Inhibiting Calpain Activation and Preserving Synaptic and Mitochondrial Function in Rats with Kainic Acid-Induced Seizure. Biomedicines 2021, 9, 284. https://doi. org /10.3390/biomedicines 9030284

Academic Editor: Susana Cardoso

Received: 10 February 2021

Accepted: 8 March 2021

Published: 10 March 2021

Publisher's Note: MDPI stays neutral with regard to jurisdictional claims in published maps and institutional affiliations.

Copyright: (C) 2021 by the authors. Licensee MDPI, Basel, Switzerland. This article is an open access article distributed under the terms and conditions of the Creative Commons Attribution (CC BY) license (https:// creativecommons.org/licenses/by/ $4.0 /)$.
1 Department of Anesthesiology, Far-Eastern Memorial Hospital, New Taipei 22060, Taiwan; drluchengwei@gmail.com (C.-W.L.); drlin1971@gmail.com (T.-Y.L.)

2 Department of Mechanical Engineering, Yuan Ze University, Taoyuan 32003, Taiwan

3 School of Traditional Chinese Medicine, Chang Gung University, Taoyuan 33302, Taiwan; pan@mail.cgu.edu.tw

4 Liver Research Center, Chang Gung Memorial Hospital, Taoyuan 33375, Taiwan

5 Department of Medical Research, China Medical University Hospital, China Medical University, Taichung 40447, Taiwan; pwwang5105@gmail.com

6 Division of Cardiovascular Surgery, Cardiovascular Center, Far-Eastern Memorial Hospital, New Taipei 22060, Taiwan; chiu9101018@gmail.com (K.-M.C.); mingyi.lee@gmail.com (M.-Y.L.)

7 Department of Nursing, Oriental Institute of Technology, New Taipei 22060, Taiwan

8 Department of Photonics Engineering, Yuan Ze University, Taoyuan 32003, Taiwan

9 School of Medicine, Fu Jen Catholic University, No.510, Zhongzheng Rd., Xinzhuang Dist., New Taipei City 24205, Taiwan

10 Research Center for Chinese Herbal Medicine, College of Human Ecology, Chang Gung University of Science and Technology, Taoyuan 33303, Taiwan

* Correspondence: med0003@mail.fju.edu.tw; Tel.: +886-(2)-29053465; Fax: +886-(2)-29052096

+ These authors contributed equally to this work.

Abstract: Cognitive impairment is not only associated with seizures but also reported as an adverse effect of antiepileptic drugs. Thus, new molecules that can ameliorate seizures and maintain satisfactory cognitive function should be developed. The antiepileptic potential of asiatic acid, a triterpene derived from the medicinal herb Centella asiatica, has already been demonstrated; however, its role in epilepsy-related cognitive deficits is yet to be determined. In this study, we evaluated the effects of asiatic acid on cognitive deficits in rats with kainic acid (KA)-induced seizure and explored the potential mechanisms underlying these effects. Our results revealed that asiatic acid administrated intraperitoneally $30 \mathrm{~min}$ prior to $\mathrm{KA}(15 \mathrm{mg} / \mathrm{kg})$ injection ameliorated seizures and significantly improved KA-induced memory deficits, as demonstrated by the results of the Morris water maze test. In addition, asiatic acid ameliorated neuronal damage, inhibited calpain activation, and increased protein kinase B (AKT) activation in the hippocampus of KA-treated rats. Asiatic acid also increased the levels of synaptic proteins and the number of synaptic vesicles as well as attenuated mitochondrial morphology damage in the hippocampus of KA-treated rats. Furthermore, proteomic and Western blot analyses of hippocampal synaptosomes revealed that asiatic acid reversed KA-induced changes in mitochondria function-associated proteins, including lipoamide dehydrogenase, glutamate dehydrogenase 1 (GLUD1), ATP synthase (ATP5A), and mitochondrial deacetylase sirtuin-3 (SIRT3). Our data suggest that asiatic acid can prevent seizures and improve cognitive impairment in KA-treated rats by reducing hippocampal neuronal damage through the inhibition of calpain activation and the elevation of activated AKT, coupled with an increase in synaptic and mitochondrial function.

Keywords: asiatic acid; epilepsy; cognitive dysfunction; kainic acid; synaptic proteins; mitochondrion proteins 


\section{Introduction}

Epilepsy is a chronic neurological disorder affecting approximately 70 million people worldwide [1]. This disease is often accompanied by numerous comorbidities, particularly learning and memory deficits [2-4]. In addition, the long-term use of anti-epileptic drugs (AEDs) can cause memory impairment in patients with epilepsy $[5,6]$. However, current antiepileptic medications only help with seizures and do not improve cognitive dysfunction. Therefore, novel therapeutic drugs that can treat epilepsy and maintain favorable cognitive function must be developed.

Recently, medicinal plant-derived substances have been highlighted because of their abilities to penetrate the blood-brain barrier, modulate neuronal activities, and prevent neuronal damage $[7,8]$. Asiatic acid (Figure $1 \mathrm{~A}$ ) is a triterpene derived from the medicinal herb Centella asiatica (L.) Urban (Apiaceae) [9]. Asiatic acid has been extensively studied using various in vitro and in vivo animal models, and it exhibits strong neuroprotective, anticonvulsive, and cognition-enhancing properties, as well as improves conditions such as cerebral ischemia, Alzheimer's disease, Parkinson's disease, and spinal cord injury [10-18]. Furthermore, studies have reported the low toxicity of asiatic acid and its ability to penetrate through the blood-brain barrier (BBB) $[19,20]$. Therefore, asiatic acid can have therapeutic potential for brain disorders, including epilepsy.

A

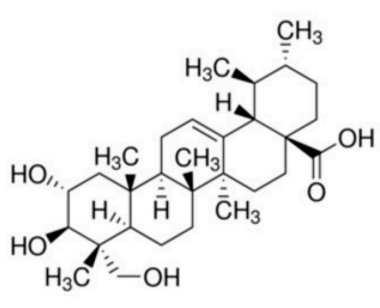

B

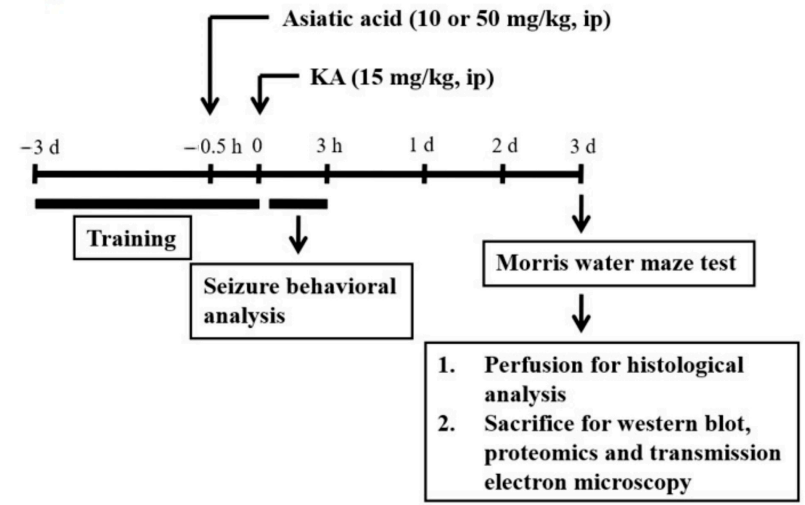

D

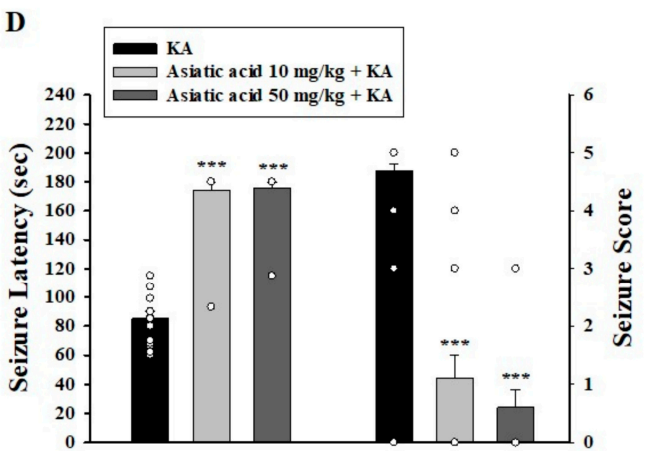

Figure 1. Asiatic acid pretreatment attenuated seizures in rats subjected to KA (kainic acid). (A) Chemical structure of asiatic acid. (B) Schematic timeline of the experimental protocol. (C) Mortality rate and (D) seizure latency and seizure score in the presence of asiatic acid versus the animals that were injected only with KA. ${ }^{* * *} p<0.001$ (vs. control); \# $p<0.001$ (asiatic acid + KA vs. KA); $n=14-20$ rats per group.

Epilepsy can be reproduced using the appropriate animal models. For example, the systemic administration of kainic acid (KA), a glutamate analog, can induce recurrent behavioral seizures, deficient cognitive functions, and disruptive morphological changes in different areas of the brain. In particular, the hippocampus has been established as a site of damage following KA administration; this damage causes cognitive dysfunction [21-23]. These pathological changes induced by KA share similarities with those found in patients 
with epilepsy [24,25]. Thus, the KA-induced seizure animal model is widely used for studying epilepsy [26]. Asiatic acid can protect against KA-induced seizures [15]; however, its preventive effects on KA-induced cognitive impairment have not been determined. In this study, we investigated the effects of asiatic acid on KA-induced cognitive deficits in rats and explored its potential underlying mechanism.

\section{Materials and Methods}

\subsection{Chemicals}

Asiatic acid (purity > 99\%, Aktin, A98688, Chengdu, China), KA (Sigma-Aldrich, K0250, St. Louis, MO, USA), dimethylsulfoxide (DMSO, Sigma-Aldrich, D8418, St. Louis, MO, USA), chloral hydrate, neutral red (Sigma-Aldrich, N2880, St. Louis, MO, USA), and general reagents were purchased from Sigma-Aldrich (St. Louis, MO, USA); Fluoro-Jade B (FJB, Histo-Chem Inc., 1FJB, Jefferson, AR, USA) was obtained from Millipore (Temecula, CA, USA).

\subsection{Animals}

A total of 68 adult male Sprague-Dawley rats ( $n=64)$ weighing between 150 and $200 \mathrm{~g}$ were purchased from BioLASCO (Taipei, Taiwan). Animals were provided food and water ad libitum and housed under a 12-h light/12-h dark cycle. Experiments were performed in accordance with approved animal protocols and guidelines established by the Animal Care Committee of Fu Jen Catholic University (Institutional Animal Care and Use Committee (IACUC) at the Fu Jen Catholic University, No. AE10561, 03 May 2017).

\subsection{Experimental Design}

Figure 1B shows the experimental design. Rats underwent the Morris water maze task for 3 days. Subsequently, they were randomly divided into four groups: DMSOtreated group (control), KA only-treated group, $10 \mathrm{mg} / \mathrm{kg}$ asiatic acid + KA group, and $50 \mathrm{mg} / \mathrm{kg}$ asiatic acid + KA group. $\mathrm{KA}(15 \mathrm{mg} / \mathrm{kg})$ dissolved in $0.9 \% \mathrm{NaCl}(\mathrm{pH} 7.0)$ was intraperitoneally (i.p.) injected to induce seizures. Asiatic acid dissolved in 1\% DMSO was administered (i.p.) $30 \mathrm{~min}$ prior to KA injection. After KA injection, seizure activity was rated during a 3-h period according to the Racine scale [27]. The time of seizure initiation and seizure scores were analyzed. After the Morris water maze test, rats were deeply anesthetized and sacrificed on the third day. To examine the immunohistochemistry of the hippocampus, rats were subjected to cardiac perfusion with normal saline, followed by $4 \%$ paraformaldehyde (PFA, Sigma-Aldrich, P6148, St. Louis, MO, USA). The brains were post-fixed with $4 \%$ PFA for $3 \mathrm{~h}$ at room temperature and then cryoprotected in $10 \%$ sucrose solution for up to 5 days at $4{ }^{\circ} \mathrm{C}$. Subsequently, $30-\mu \mathrm{m}$ coronal sections of the fixed brain were cut using a standard microtome, and 5-in-1 series of brain sections throughout the hippocampus were collected in wells containing antifreeze (20\% glycerol and $30 \%$ ethylene glycol) solution and stored at $-20^{\circ} \mathrm{C}$. In addition, another set of animals $(n=20)$ were deeply anesthetized and rapidly decapitated on the third day after administering KA. Fresh brain tissues from both the hippocampi were collected for synaptosomal preparation and Western blot analysis. The KA dose and administration schedule were chosen based on previous experiments [28-30].

\subsection{Morris Water Maze Test}

The Morris water maze test was performed to evaluate the spatial learning and memory of rats, as described previously [31]. During the first 3 days, rats were trained to find a platform $(10 \mathrm{~cm}$ in diameter) hidden $2 \mathrm{~cm}$ below the water surface level in a circular pool (200 $\mathrm{cm}$ in diameter and $50 \mathrm{~cm}$ in depth) at a fixed location. The apparatus was filled with water $\left(2{ }^{\circ} \mathrm{C} \pm 1{ }^{\circ} \mathrm{C}\right)$ to a depth of approximately $35 \mathrm{~cm}$. The pool was virtually divided into four equal-size quadrants. On each day of training, a rat was placed in a different quadrant facing the pool wall and was trained to find the escape platform within $120 \mathrm{~s}$. If the platform was not found within $120 \mathrm{~s}$, the rat was guided to the platform 
by the experimenter. Each rat was allowed to remain on the platform for $30 \mathrm{~s}$ during each trial. Each rat performed four training trials daily for 3 consecutive days, with an interval of approximately $60 \mathrm{~s}$ between trials. The latency (time taken to find the escape platform) and the swimming distances were recorded using a video tracking system (Version 1.17, SINGA Technology Corporation, Taipei, Taiwan).

\subsection{Neutral Red and FJB Staining}

Neutral red staining was performed to examine the general histology. The brain sections were mounted on gelatinized slides and stained with $1 \%$ neutral red. Each stained section was observed using a light microscope to assess the degree of neuronal loss within the hippocampus. FJB staining of the degenerating neurons was performed on another set of brain sections, as described previously [31]. Briefly, the sections were mounted on gelatinized slides and immersed in 100\% ethanol ( $3 \mathrm{~min}), 70 \%$ ethanol ( $2 \mathrm{~min})$, and distilled water $(2 \mathrm{~min})$. Subsequently, the sections were incubated in $0.06 \%$ potassium permanganate (J.T. Baker Inc., 3227-01, Phillipsburg, NJ, USA) for $15 \mathrm{~min}$, washed twice in distilled water, and immersed in FJB solution (0.001\% FJB/0.1\% acetic acid) for $30 \mathrm{~min}$ in darkness. The potassium permanganate pretreatment not only confers considerable resistance to fading, but also minimizes background staining. After washing three times in distilled water, the slides were air dried in the dark for $20 \mathrm{~min}$, dehydrated in xylene (9490-03), and coverslipped using dibutyl phthalate in xylene medium. Images were acquired using an upright fluorescence microscope (Zeiss Axioskop 40, Göttingen, Lower Saxony, Germany). Leica $4 \mathrm{X}$ or $10 \mathrm{X}$ objective lenses with a numerical aperture (NA) of 0.1 or 0.25 were used in this study (Wetzlar, Germany). To compare neuronal death among the experimental groups, the numbers of surviving neurons and Fluoro-Jade B-positive cells was counted in a $255 \times 255 \mu \mathrm{m}^{2}$ area of the hippocampal Cornu Ammonis 1 (CA1) and CA3 in 6-8 randomly chosen sections from each animal and averaged for each animal using Image $\mathrm{J}$ by an examiner blind to the experimental conditions. Results are expressed as the mean \pm standard error of mean (SEM) of the labeled cells per $0.1 \mathrm{~mm}^{2}$.

\subsection{Synaptosomal Preparation and Transmission Electron Microscopy}

Synaptosomes were prepared from male Sprague-Dawley rats as described previously [30,32]. Briefly, rats ( $n=3$ /group) were sacrificed through rapid decapitation, and the hippocampus was removed and homogenized in $0.32 \mathrm{M}$ sucrose. After centrifugation (5000 rpm for $10 \mathrm{~min}$ ), the supernatant was placed into Percoll (Sigma-Aldrich, P1644, St. Louis, MO, USA) discontinuous gradients (3\%, 10\% and $23 \%$ ) and centrifuged at $16,500 \mathrm{rpm}$ for $7 \mathrm{~min}$. The synaptosomal fraction between $10 \%$ and $23 \%$ Percoll bands was collected and centrifuged for $10 \mathrm{~min}$ at 15,000 rpm. Synaptosomes were fixed in 4\% PFA and $2.5 \%$ glutaraldehyde for 1 day. The fixed hippocampal synaptosomes were washed in PBS, postfixed in 1\% osmium tetraoxide for $2 \mathrm{~h}$, dehydrated, and embedded in epoxy resin. Subsequently, 70-nm-thick sections were cut using an ultramicrotome (EM UC7, Leica Microsystems, Wetzlar, Germany). The ultrastructure of the hippocampal synaptosome was observed under a transmission electron microscope (JEM-1400, JEOL, Tokyo, Japan).

\subsection{Proteomics}

The two-dimensional electrophoresis (2-DE) procedure is described in a previous study [33]. Briefly, protein extracts $(180 \mu \mathrm{g})$ were applied to ImmobilineDrystrip ( $\mathrm{pH}$ 4-7, 18-cm IPG strip, GE Healthcare, Chicago, IL, USA) and separated on the IPGphor III System to evaluate the first dimension. The 2-DE procedure was performed using $10 \%$ acrylamide gels (Bio-Rad, Hercules, CA, USA), and the protein images were visualized through silver staining. All gels were scanned and quantified using Prodigy SameSpots software (Nonlinear Dynamics, Newcastle, UK). Each spot intensity volume (\%) was determined through the background subtraction technique and the total spot volume normalization method for comparison among groups. More than 2.0-fold alterations at 95\% 
confidence intervals $(p<0.05)$ were considered statistically significant. All experiments were repeated three times to confirm reproducibility.

Spots of interest were excised, and in-gel digested with trypsin as described previously [34]. After digestion, tryptic peptides were acidified with $0.5 \%$ trifluoroacetic acid and loaded onto an MTP AnchorChip ${ }^{\mathrm{TM}}$ 600/384 TF (Bruker-Daltonik, Bremen, Germany). Mass spectrometry analysis was performed using an Ultraflex ${ }^{\mathrm{TM}}$ MALDI-TOF mass spectrometer (Bruker-Daltonik, Bremen, Germany). Monoisotopic peptide masses were assigned and used for database searches in the MASCOT search engine (Matrix Science, London, UK). Search parameters were set as follows: a maximum allowed peptide mass error of $50 \mathrm{ppm}$ and the consideration of one incomplete cleavage per peptide.

\subsection{Biological Network Analysis Using MetaCore ${ }^{\mathrm{TM}}$}

MetaCore $^{\mathrm{TM}}$ software (version 5.2 build 17389, GeneGo, St. Joseph, MI, USA) was utilized to elucidate the ontological classes and relevant pathways represented by genes identified in 2-DE and peptide mass fingerprinting. We used two algorithms for the network analysis: (i) the analysis network algorithm, to deduce the scoring processes regulated by the differentially expressed proteins; and (ii) the shortest path algorithm, to build a network consisting of the smallest possible number of direct interactions between the differentially expressed proteins. The statistical relevance of the ontological matches was calculated as the $p$ value [35].

\subsection{Western Blotting}

The sample preparation procedure and conditions for Western blot analysis are described previously [36]. In brief, the hippocampi or hippocampal synaptosomes were homogenized, and equal amounts of protein were subjected to sodium dodecylsulfate polyacrylamide gel electrophoresis and blotted onto nitrocellulose membranes. Subsequently, membranes were first incubated for $1 \mathrm{~h}$ in $5 \%$ non-fat milk and then overnight at $4{ }^{\circ} \mathrm{C}$ with primary antibodies. The antibodies used were anti-calpain 1 (1:1000, Abcam, ab28258, Cambridge, UK), anti-calpain 2 (1:800, Millipore, MAB3083, Temecula, CA, USA), anti-calpastatin (1:300, Proteintech, 12250-1-AP, Rosemont, IL, USA), anti-protein kinase B (AKT, 1:10,000, Cell Signaling, \#9272, Beverly, MA, USA), anti-pAKT (1:10000, Cell Signaling, \#9271, Beverly, MA, USA), anti-synaptophysin (1:100,000, Cell Signaling, \#36406, Beverly, MA, USA), anti-synaptotagmin (1:1000, Abcam, ab13259, Cambridge, UK), antisynaptobrevin (1:800, Abcam, ab18013, Cambridge, UK), anti-synapsin I (1:100,000, Cell Signaling, \#5297, Beverly, MA, USA), anti-synaptosomal-associated protein $25 \mathrm{kDa}$ (SNAP 25, 1:6000, Abcam, ab41455, Cambridge, UK), anti-postsynaptic density protein 95 (PSD 95, 1:600, Abcam, ab2723, Cambridge, UK), anti-lipoamide dehydrogenase (1:20,000, Abcam, ab133551, Cambridge, UK), anti-glutamate dehydrogenase 1 (GLUD1, 1:1000, Invitrogen, \#PA5-28301, Waltham, MA, USA), anti-mitochondrial membrane ATP synthase (ATP5A, 1:3000, Abcam, ab14748, Cambridge, UK), anti-mitochondrial deacetylase sirtuin-3 (SIRT3, 1:800, Abcam, ab270523, Cambridge, UK), and anti- $\beta$-actin (1:1000, Cell Signaling, \#3700, Beverly, MA, USA), which served as a control of the protein load. The membranes were washed three times (Tris-buffered saline, TBS, 10 min each), incubated with horseradish peroxidase-conjugated secondary antibodies (1:2000, Gentex, GTX213110-01, GTX21311101, Zeeland, MI, USA) for $1 \mathrm{~h}$, and washed with TBS three times (10 min each), followed by detection using the enhanced chemiluminescence system (Amersham Biosciences Corp., Amersham, Buckinghamshire, UK) and quantification using Image J analysis software (Synoptics, Cambridge, UK).

\subsection{Statistical Analyses}

The results are expressed as the mean \pm SEM and were analyzed using one-way analysis of variance (ANOVA), followed by Tukey's post-hoc test to determine the difference. Differences were considered statistically significant at $p<0.05$. 


\section{Results}

\subsection{Asiatic Acid Reduced the Mortality Rate and Seizures in Rats Receiving $K A$}

$\mathrm{KA}(15 \mathrm{mg} / \mathrm{kg}$, i.p.) induced seizures in $91 \%$ of injected rats, with a mortality rate of $30 \%$. Asiatic acid (10 and $50 \mathrm{mg} / \mathrm{kg}$ ) administered (i.p.) $30 \mathrm{~min}$ prior to KA administration significantly reduced the mortality rate to $6 \%$ (Figure $1 \mathrm{C}$ ). In addition, we observed that asiatic acid pretreatment delayed seizure initiation $(F(2,42)=103.6, p<0.001$; Figure 1D) and reduced the severity of seizures compared with only KA treatment $(F(2,51)=42.3$, $p<0.001$; Figure 1D).

\subsection{Asiatic Acid Improved Learning and Memory Deficits in Rats with KA-Induced Seizures}

To investigate the effect of asiatic acid on learning and memory, rats were subjected to the Morris water maze test (Figure 2A). The time taken to locate the escape platform and the total distance traveled are shown in Figure 2B. We observed that the KA-treated rats required a longer time to reach the platform than did the control rats $(p<0.001)$. Pretreatment of the KA-treated rats with asiatic acid significantly shortened the escape time compared with rats with KA treatment alone $(F(3,45)=224.9, p<0.001)$. The KA group showed an increase in the total distance traveled to reach the platform compared with the control group $(p<0.001)$. Pretreatment with asiatic acid significantly reduced the total distance traveled compared with KA treatment alone $(F(3,37)=202.9, p<0.001$; Figure $2 \mathrm{~B})$. No difference in the total distance traveled was noted between the groups treated with asiatic acid and the control group $(p=0.99)$.
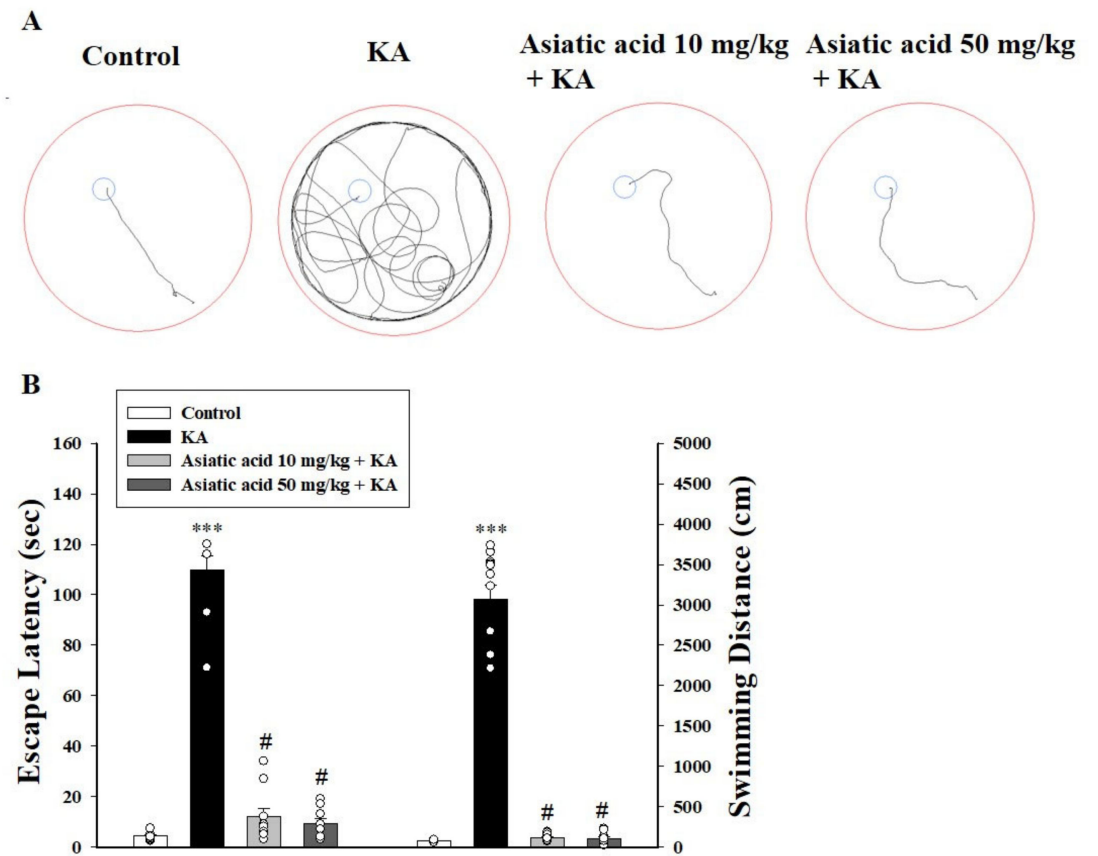

Figure 2. Effect of asiatic acid pretreatment on spatial learning and memory in rats with KA (kainic acid)-induced seizures. (A) Swimming tracks of rats in the Morris water maze test. (B) Mean escape latency to reach the platform and total distance traveled to reach the platform. ${ }^{* * *} p<0.001$ (vs. control); $\# p<0.001$ (asiatic acid + KA vs. KA); $n=8-13$ rats per group.

\subsection{Asiatic Acid Attenuated Neuronal Damage in the Hippocampus of Rats with} KA-Induced Seizures

Hippocampal neuronal damage induced by KA can lead to cognitive impairment [37]. Therefore, we evaluated the effect of asiatic acid on neuronal damage after rats underwent the Morris water maze test. As shown in Figure 3A, cell viability in the hippocampus was examined through neutral red staining. Cell viability in the CA1 and CA3 areas of the hippocampus 3 days after KA treatment was significantly lower than that in the control 
group. Cell survival in the CA1 and CA3 areas of the hippocampus was significantly higher in the asiatic acid pretreatment group than in the KA-only treated group (CA1, $F(3,12)=219.5, p<0.001$; CA3, $F(3,12)=376.9, p<0.001$; Figure 3A,B). The protective effect of asiatic acid was also observed through FJB staining, which shows cells undergoing neurodegeneration. As shown in Figure 3A, no cells were stained with FJB in the control rats. By contrast, abundant FJB-positive cells were observed in the CA1 and CA3 regions of the KA-treated rats. In rats pretreated with asiatic acid, no FJB-positive cells were found in the CA1 and CA3 regions. These findings were corroborated by one-way ANOVA results that revealed that KA administration significantly increased the number of FJBpositive cells and that asiatic acid significantly suppressed this effect $(C A 1, F(3,12)=1536.2$, $p<0.001 ; C A 3, F(3,12)=2424.6, p<0.001$; Figure 3C). However, no such differences were noted between groups treated with asiatic acid and the control group $(p=1)$.

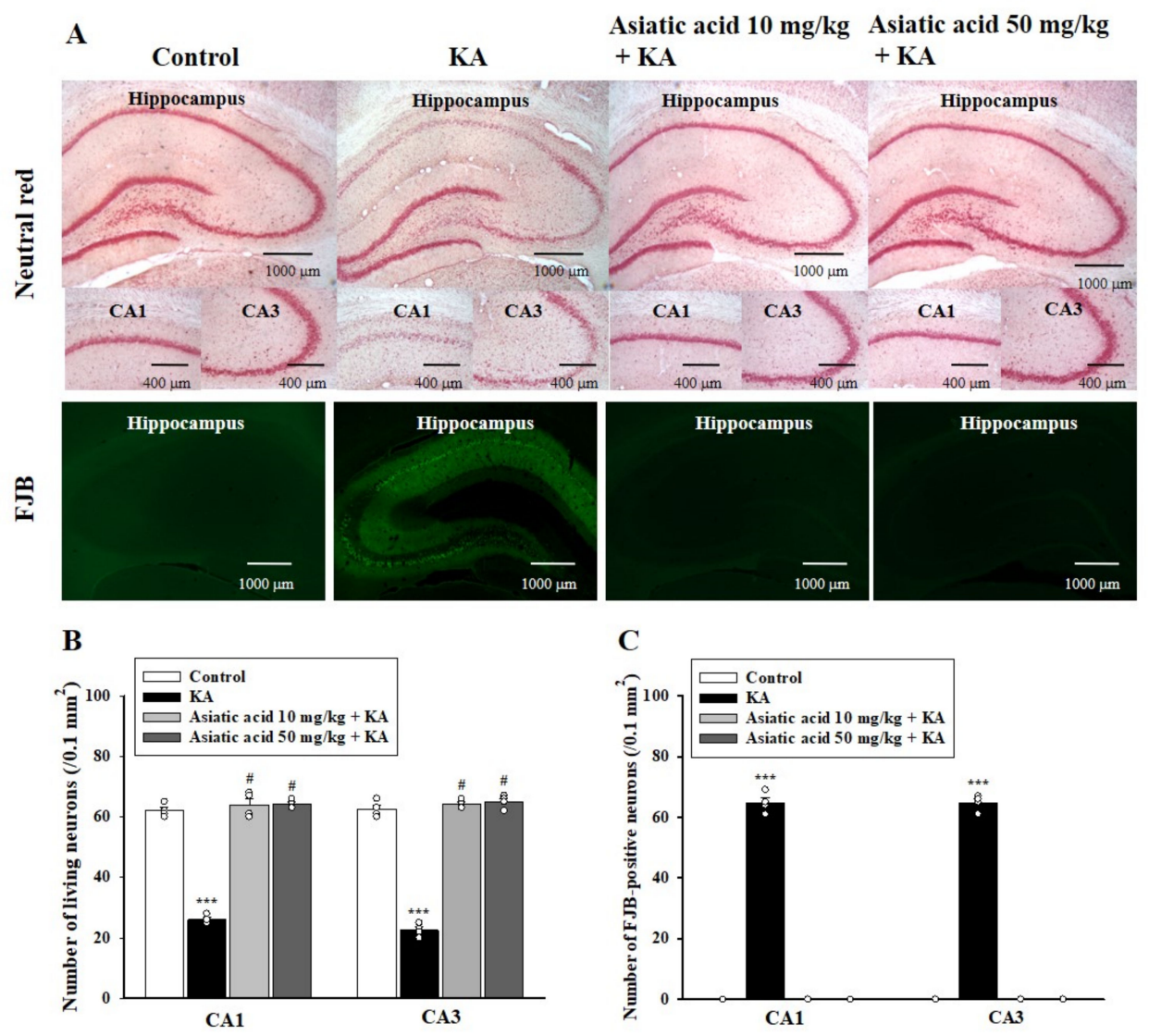

Figure 3. Effects of asiatic acid pretreatment on neuronal damage in the hippocampus of rats with KAinduced seizures. (A) Representative images showing neutral red and FJB (Fluoro-Jade B) staining in the hippocampus. The number of surviving neurons (B) and FJB-positive neurons $(\mathbf{C})$ in the hippocampal CA1 and CA3 regions was counted. ${ }^{* * *} p<0.001$ (vs. control); $\#<0.001$ (asiatic acid + KA vs. KA); $n=4$ rats per group. Scale bar: $400-1000 \mu \mathrm{m}$.

3.4. Asiatic Acid Suppressed Calpain Activation and AKT Inactivation in the Hippocampus of Rats with KA-Induced Seizures

Calpains are calcium-dependent proteases involved in neuronal death induced by KA [38,39]. Calpain inhibition through calpastatin, the endogenous inhibitor of calpains, can protect against KA-induced hippocampal neuronal damage and cognitive dysfunction [40]. Therefore, we examined the effect of asiatic acid on the expression of calpains and calpastatin in KA-treated rats. As shown in Figure 4A, $72 \mathrm{~h}$ after KA administration, the calpain level in the hippocampus was significantly higher in the KA-treated group than in the control group $(p<0.001)$. The expression of calpains in the hippocampus was significantly decreased in the group pretreated with asiatic acid compared with the KA-treated 
group (calpain 1, F $(3,16)=59.1, p<0.001$; calpain $2, F(3,16)=21.7, p<0.001)$. By contrast, the calpastatin level was decreased in the hippocampus of the KA-treated group compared with the control group $(p<0.001)$; however, the decreased levels were reversed by pretreatment with asiatic acid compared with the $\operatorname{KA}$ group $(F(3,16)=19.6, p<0.001$; Figure 4A). In addition, we examined whether asiatic acid treatment contributed to the upregulation of survival signaling through AKT, resulting in neuronal cell survival [41,42]. As shown in Figure $4 \mathrm{~B}$, the phosphorylation of AKT (p-AKT) decreased in the hippocampus of the KA-treated group compared with the control group $(p<0.001)$. Asiatic acid pretreatment restored the decreased $\mathrm{p}$-AKT level $(F(3,16)=22.4, p<0.001)$.

A
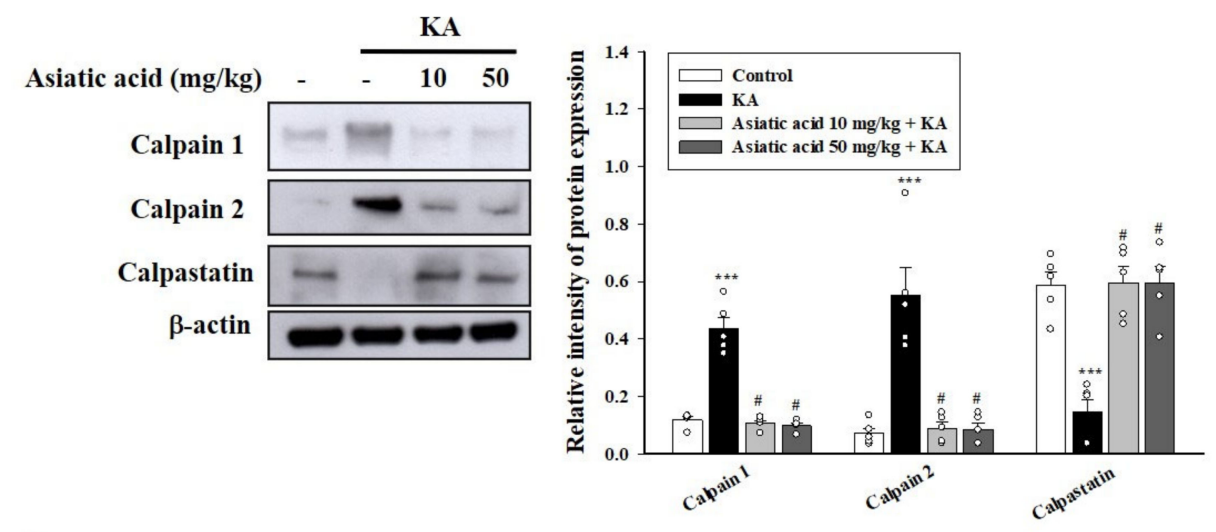

B
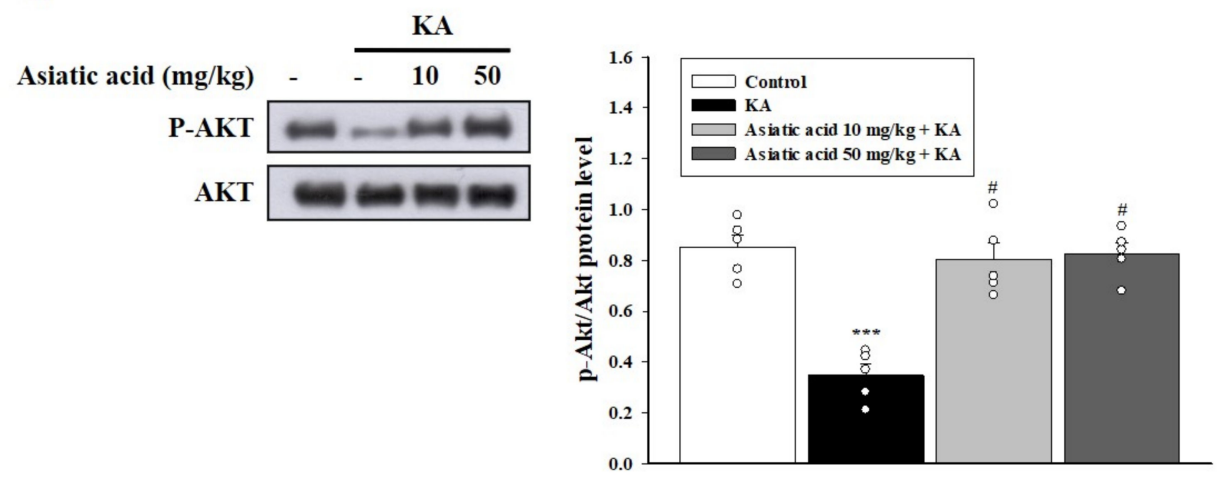

Figure 4. Effects of asiatic acid pretreatment on the levels of calpain, calpastatin, and p-AKT (protein kinase B) in the hippocampus of rats with KA-induced seizures. (A,B) Western blot showing the expression levels of calpain, calpastatin, and $\mathrm{p}-\mathrm{AKT}$ in the hippocampus for each group. The relative protein levels were quantified. ${ }^{* *} p<0.001$ (vs. control); $\# p<0.001$ (asiatic acid + KA vs. KA); $n=5$ rats per group.

\subsection{Asiatic Acid Preserved the Levels of Synaptic Proteins in the Hippocampus of Rats with KA-Induced Seizures}

Synaptic proteins, a marker of synaptic activity and plasticity, play a key role in maintaining cognitive function, and their levels have been demonstrated to be decreased in KA-induced excitotoxic injury $[23,43]$. Therefore, we examined the levels of several synaptic marker proteins in the hippocampus of rats with KA-induced seizures. As shown in Figure 5A, the levels of presynaptic proteins (synaptophysin, synaptotagmin, synaptobrevin, synapsin-1, and SNAP-25) were decreased in the hippocampus of the KA-treated group compared with the control group $(p<0.001)$. Rats pretreated with asiatic acid exhibited significantly higher levels of presynaptic proteins compared with the KA-treated rats (synaptophysin, $F(3,16)=23.1, p<0.001$; synaptotagmin, $F(3,16)=20.1, p<0.001$; synaptobrevin, $F(3,16)=53.4, p<0.001$; synapsin- $1, F(3,16)=23.3, p<0.001$; SNAP-25, $F(3,16)=82.9, p<0.001)$. The level of the postsynaptic protein PSD-95 in the hippocam- 
pus also demonstrated a significant decline in the KA-treated group compared with the control group $(p<0.001)$. These decreases were reversed by asiatic acid pretreatment $(F(3,16)=15.1, p<0.001$; Figure 5A). In addition, the expression levels of the presynaptic proteins were markedly decreased in the hippocampal synaptosomes of the KA-treated group compared with the control group $(p<0.001)$. Pretreatment with asiatic acid significantly restored the expression of these proteins compared with that in the KA-treated group (synaptophysin, $F(3,16)=7.2, p<0.01$; synaptotagmin, $F(3,16)=28.3, p<0.001$; synaptobrevin, $F(3,16)=28.8, p<0.001$; synapsin-1, $F(3,16)=18.8, p<0.001$; SNAP-25, $F(3,16)=18.4, p<0.001 ;$ Figure 5B).

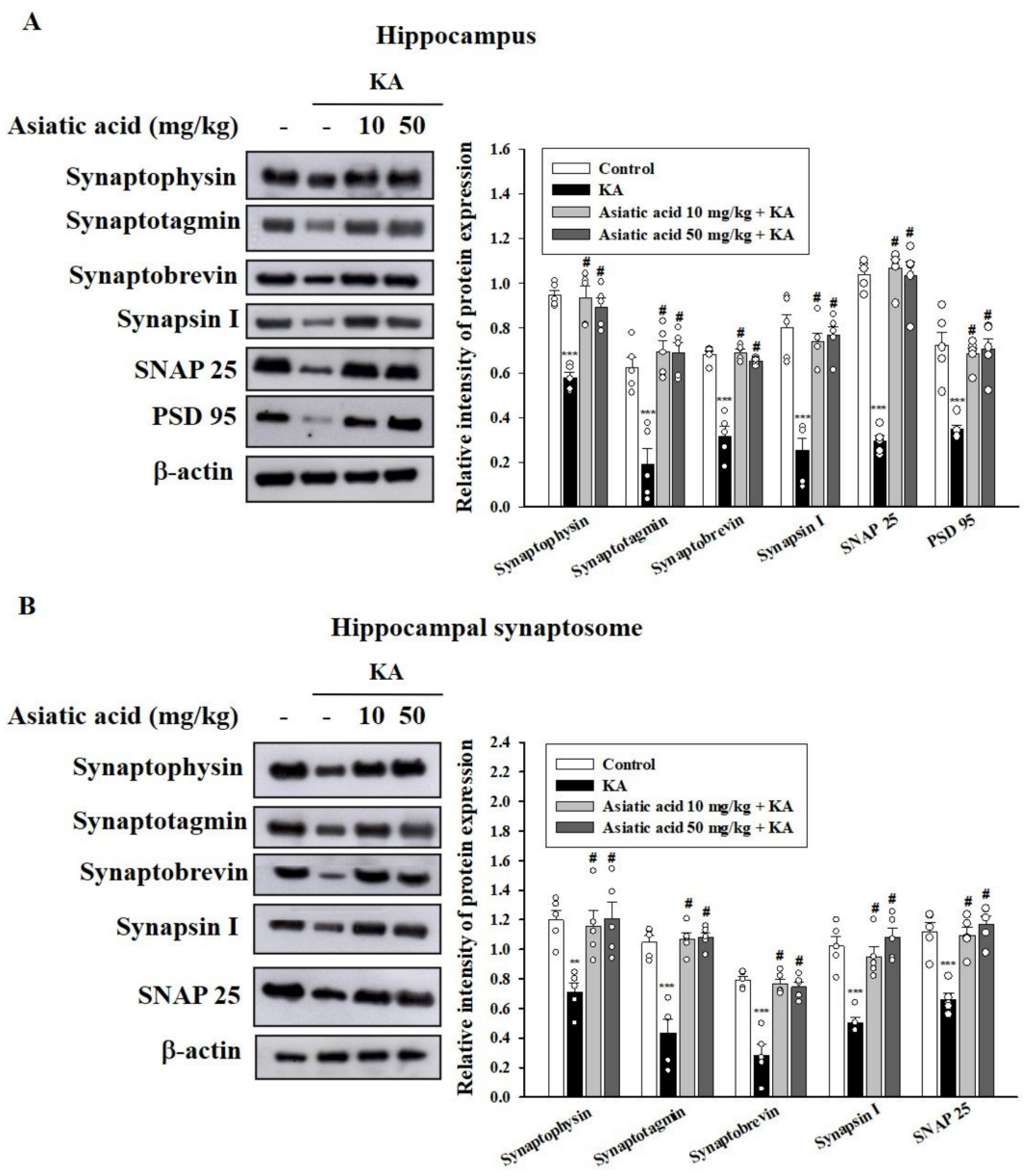

Figure 5. Effects of asiatic acid pretreatment on the levels of synaptic proteins in the hippocampus of rats with KA-induced seizures. Western blot showing the expression levels of synaptophysin, synaptobrevin, synaptotagmin, synapsin-1, and SNAP-25 (synaptosomal-associated protein $25 \mathrm{kDa}$ ) in the hippocampal tissues (A) and hippocampal synaptosomes (B) for each group. The relative protein levels were quantified. ${ }^{* *} p<0.01,{ }^{* * *} p<0.001$ (vs. control); $\# p<0.001$ (asiatic acid + KA vs. $\mathrm{KA}) ; n=5$ rats per group.

\subsection{Asiatic Acid Prevented the Decline in Synaptic Vesicles and Mitochondrial Morphology Damage in the Hippocampal Synaptosomes of Rats with KA-Induced Seizures}

Because we observed a decline in the levels of presynaptic proteins under seizure and cognitive dysfunction induced by KA, we used transmission electron microscopy to examine the ultrastructure of the hippocampal nerve terminals (synaptosomes). Figure 6A shows that the hippocampal synaptosome of the control group contained mitochondria, numerous synaptic vesicles, and a synaptic junction with postsynaptic density. By contrast, decreased synaptic vesicles and mitochondrial swelling and disruption were observed in the hippocampal synaptosome of KA-treated rats. In rats pretreated with asiatic acid, 
the KA-caused synaptic vesicle reduction and the mitochondrial structural damage was ameliorated. As shown in Figure 6B, we observed a significant decrease in the number of synaptic vesicles per synaptosome in the KA group compared with the control group $(p<0.01)$; however, the no difference in the number of synaptic vesicles per synaptosome was observed between the asiatic acid groups and the control group $(p=1)$. We noted a significant increase in the number of synaptic vesicles in the groups pretreated with asiatic acid in comparison with the KA-treated group $(F(3,8)=8.9, p<0.01)$.
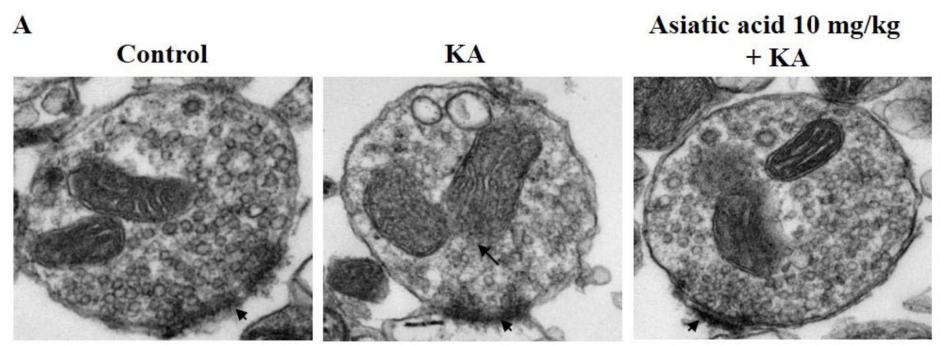

Asiatic acid $50 \mathrm{mg} / \mathrm{kg}$

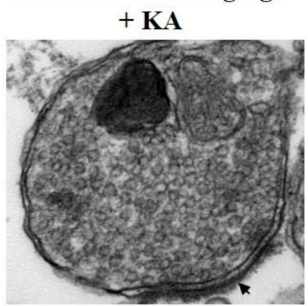

B

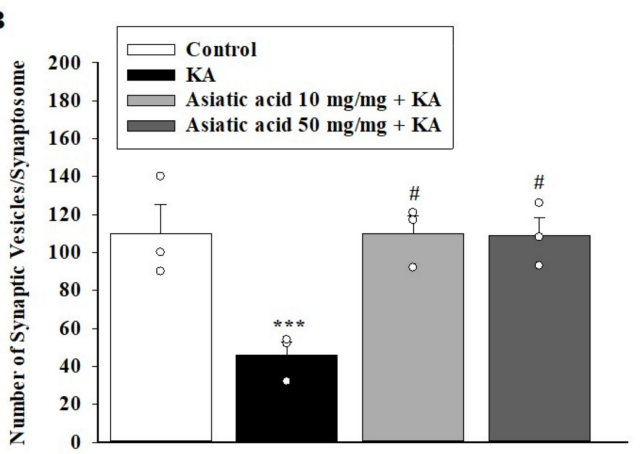

Figure 6. (A) Representative transmission electron micrographs of the hippocampal synaptosomal ultrastructure. Each synaptosome contains mitochondria, numerous synaptic vesicles, and a synaptic junction with postsynaptic density (arrowhead). Severe mitochondrial swelling accompanied by a disruption in membrane integrity (arrows). Scale bar, $200 \mathrm{~nm}$. (B) The number of synaptic vesicles in the hippocampal synaptosomes was counted. ${ }^{* * *} p<0.001$ (vs. control); \# $p<0.001$ (asiatic acid + KA vs. KA); $n=3$ rats per group.

\subsection{Proteomic Analysis Identified 12 Proteins Associated with the Effect of Asiatic Acid on the} Hippocampal Synaptosomes of Rats with KA-Induced Seizures

To explore the specific proteins and potential mechanisms underlying the asiatic acid-mediated cognitive improvement in rats with KA-induced seizures, we performed a proteomic analysis of the hippocampal synaptosomes to identify the proteins responsive to asiatic acid treatment. As shown in Figure 7A, approximately 780 protein spots appeared in each gel, and the MS analysis clearly identified significant changes in the expression levels of 12 proteins (labeled with Arabic numerals in Table 1). Moreover, a group of mitochondrial proteins was identified, including dihydrolipoyl dehydrogenase, glutamate dehydrogenase 1 (GLUD1), aconitatehydratase, and ATP synthase subunits, which are majorly associated with energy generation and various metabolic pathways. In addition, the results of the Western blot analysis revealed that the levels of lipoamide dehydrogenase, GLUD1, ATP5A, and mitochondrial deacetylase SIRT3 decreased in the hippocampal synaptosomes of the KA-treated group compared with the control group $(p<0.001)$. Rats pretreated with asiatic acid exhibited significantly higher levels of lipoamide dehydrogenase, GLUD1, AT5A, and SIRT3 than did rats treated with KA alone (lipoamide dehydrogenase, $F(3,16)=9.3 .7, p<0.01$; GLUD1, $F(3,16)=93.1, p<0.001$; ATP5A, $F(3,16)=12.9$, $p<0.001$; SIRT3, $F(3,16)=20.1, p<0.001$; Figure 7B) 
Table 1. List of identified protein spots.

\begin{tabular}{|c|c|c|c|c|c|c|c|}
\hline Spot No. & Protein Name & Accession Number & Mw/pI & Score (Coverage) & $\begin{array}{c}\text { Match } \\
\text { Fragment }\end{array}$ & $\begin{array}{l}\text { Subcellular } \\
\text { Location }\end{array}$ & Function \\
\hline 1 & $\begin{array}{l}\text { Tubulin alpha-1A } \\
\text { chain }\end{array}$ & P68370 & $50.788 / 4.94$ & $69(35 \%)$ & 9 & $\begin{array}{l}\text { Cytoplasm, } \\
\text { cytoskeleton. }\end{array}$ & $\begin{array}{l}\text { Tubulin is the major constituent of microtubules. It } \\
\text { binds two moles of GTP, one at an exchangeable site } \\
\text { on the beta chain and one at a non-exchangeable site } \\
\text { on the alpha chain. }\end{array}$ \\
\hline 2 & $\begin{array}{l}\text { Dihydrolipoyl } \\
\text { dehydrogenase }\end{array}$ & Q6P6R2 & $54.574 / 7.96$ & $113(27 \%)$ & 12 & $\begin{array}{l}\text { Mitochondrion } \\
\text { matrix }\end{array}$ & $\begin{array}{l}\text { Lipoamide dehydrogenase is a component of the } \\
\text { glycine cleavage system as well as an E3 component } \\
\text { of three alpha-ketoacid dehydrogenase complexes } \\
\text { (pyruvate-, alpha-ketoglutarate-, and branched- } \\
\text { chain amino acid-dehydrogenase complex). }\end{array}$ \\
\hline 3 & $\begin{array}{c}\text { Glutamate } \\
\text { dehydrogenase } 1\end{array}$ & P10860 & $61.719 / 8.05$ & $89(28 \%)$ & 12 & $\begin{array}{l}\text { Mitochondrion } \\
\text { Endoplasmic } \\
\text { reticulum }\end{array}$ & $\begin{array}{l}\text { Mitochondrial glutamate dehydrogenase that } \\
\text { converts L- glutamate into alpha-ketoglutarate. Plays } \\
\text { a key role in glutamine anaplerosis by producing } \\
\text { alpha-ketoglutarate, an important intermediate in } \\
\text { the tricarboxylic acid cycle (By similarity). May be } \\
\text { involved in learning and memory reactions by } \\
\text { increasing the turnover of the excitatory } \\
\text { neurotransmitter glutamate (PubMed:9275181). }\end{array}$ \\
\hline 4 & $\begin{array}{l}\text { Aconitate } \\
\text { hydratase }\end{array}$ & Q9ER34 & $86.121 / 7.87$ & $159(29 \%)$ & 16 & Mitochondrion & $\begin{array}{l}\text { Catalyzes the isomerization of citrate to isocitrate via } \\
\text { cis-aconitate. }\end{array}$ \\
\hline 5 & $\begin{array}{l}\text { Pyruvate } \\
\text { dehydrogenase } \\
\text { E1 component } \\
\text { subunit beta }\end{array}$ & P49432 & $39.299 / 6.20$ & $130(46 \%)$ & 12 & $\begin{array}{l}\text { Mitochondrion } \\
\text { matrix }\end{array}$ & $\begin{array}{l}\text { The pyruvate dehydrogenase complex catalyzes the } \\
\text { overall conversion of pyruvate to acetyl-CoA and } \\
\mathrm{CO}_{2} \text {, and thereby links the glycolytic pathway to the } \\
\text { tricarboxylic cycle. }\end{array}$ \\
\hline 6 & Alpha-enolase & P04764 & $47.44 / 6.16$ & $223(56 \%)$ & 22 & $\begin{array}{l}\text { Cytoplasm. } \\
\text { Cell membrane. }\end{array}$ & $\begin{array}{l}\text { Glycolytic enzyme the catalyzes the conversion of 2- } \\
\text { phosphoglycerate to phosphoenolpyruvate. In } \\
\text { addition to glycolysis, involved in various processes } \\
\text { such as growth control, hypoxia tolerance and } \\
\text { allergic responses. May also function in the } \\
\text { intravascular and pericellular fibrinolytic system due } \\
\text { to its ability to serve as a receptor and activator of } \\
\text { plasminogen on the cell surface of several cell-types } \\
\text { such as leukocytes and neurons. }\end{array}$ \\
\hline
\end{tabular}


Table 1. Cont.

\begin{tabular}{|c|c|c|c|c|c|c|c|}
\hline Spot No. & Protein Name & Accession Number & Mw/pI & Score (Coverage) & $\begin{array}{c}\text { Match } \\
\text { Fragment }\end{array}$ & $\begin{array}{l}\text { Subcellular } \\
\text { Location }\end{array}$ & Function \\
\hline 7 & $\begin{array}{l}\text { Tubulin beta-2A } \\
\text { chain }\end{array}$ & P85108 & $50.274 / 4.78$ & $290(59 \%)$ & 29 & $\begin{array}{l}\text { Cytoplasm, } \\
\text { cytoskeleton }\end{array}$ & $\begin{array}{l}\text { Tubulin is the major constituent of microtubules. It } \\
\text { binds two moles of GTP, one at an exchangeable site } \\
\text { on the beta chain and one at a non-exchangeable site } \\
\text { on the alpha chain (By similarity). }\end{array}$ \\
\hline 8 & $\begin{array}{l}\text { Dihydropyrimidinase- } \\
\text { related protein } \\
\quad 2\end{array}$ & P47942 & $62.638 / 5.95$ & $217(45 \%)$ & 20 & Cytoplasm & $\begin{array}{l}\text { Plays a role in neuronal development and polarity, as } \\
\text { well as in axon growth and guidance, neuronal } \\
\text { growth cone collapse and cell migration. Necessary } \\
\text { for signaling by class } 3 \text { semaphorins and subsequent } \\
\text { remodeling of the cytoskeleton. }\end{array}$ \\
\hline 9 & $\begin{array}{l}\text { ATP synthase } \\
\text { subunit alpha }\end{array}$ & P15999 & $59.831 / 9.22$ & $205(45 \%)$ & 22 & Mitochondrion & $\begin{array}{l}\text { Mitochondrial membrane ATP synthase }\left(\mathrm{F}_{1} \mathrm{~F}_{0} \text { ATP }\right. \\
\text { synthase or Complex } \mathrm{V}) \text { produces ATP from ADP in } \\
\text { the presence of a proton gradient across the } \\
\text { membrane which is generated by electron transport } \\
\text { complexes of the respiratory chain. }\end{array}$ \\
\hline 10 & $\begin{array}{l}\text { ATP synthase } \\
\text { subunit beta }\end{array}$ & P10719 & $56.318 / 5.19$ & $266(64 \%)$ & 33 & $\begin{array}{l}\text { Mitochondrion inner } \\
\text { membrane }\end{array}$ & $\begin{array}{l}\text { During catalysis, ATP synthesis in the catalytic } \\
\text { domain of } F_{1} \text { is coupled via a rotary mechanism of } \\
\text { the central stalk subunits to proton translocation. } \\
\text { Subunits alpha and beta form the catalytic core in } F_{1} \text {. }\end{array}$ \\
\hline 11 & $\begin{array}{l}\text { V-type proton } \\
\text { ATPase subunit B }\end{array}$ & P62815 & $56.857 / 5.57$ & $276(61 \%)$ & 26 & Membrane & $\begin{array}{l}\text { Non-catalytic subunit of the peripheral V1 complex } \\
\text { of vacuolar ATPase. V-ATPase is responsible for } \\
\text { acidifying a variety of intracellular compartments in } \\
\text { eukaryotic cells. }\end{array}$ \\
\hline 12 & $\begin{array}{l}\text { Dihydrolipoyllysine- } \\
\text { residue } \\
\text { succinyltrans- } \\
\text { ferase component } \\
\text { of 2-oxoglutarate } \\
\text { dehydrogenase } \\
\text { complex }\end{array}$ & Q01205 & $49.236 / 8.89$ & $75(20 \%)$ & 8 & $\begin{array}{l}\text { Mitochondrion } \\
\text { matrix }\end{array}$ & $\begin{array}{l}\text { The 2-oxoglutarate dehydrogenase complex } \\
\text { catalyzes the overall conversion of 2-oxoglutarate to } \\
\text { succinyl-CoA and } \mathrm{CO}_{2} \text { (By similarity). The } \\
\text { 2-oxoglutarate dehydrogenase complex is mainly } \\
\text { active in the mitochondrion. }\end{array}$ \\
\hline
\end{tabular}




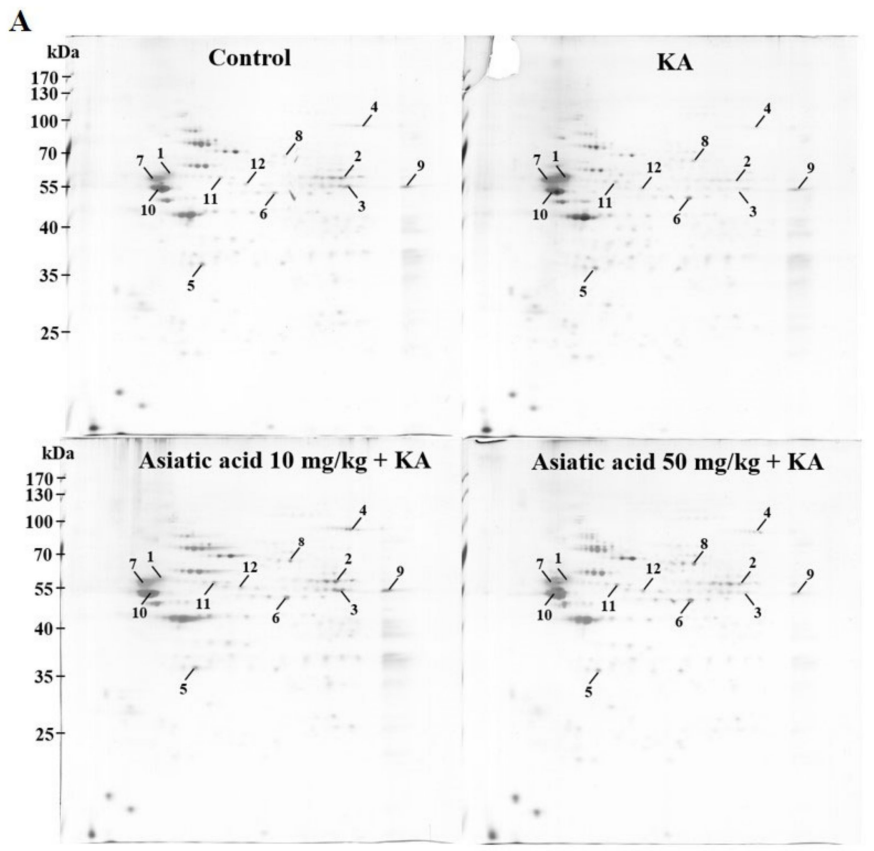

B

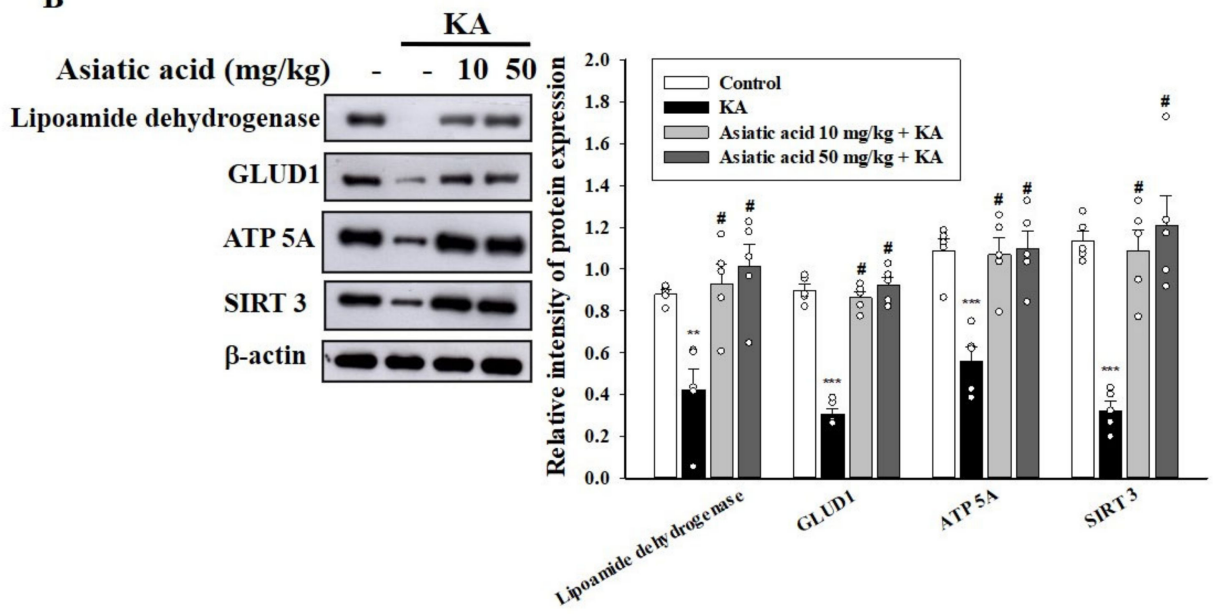

Figure 7. (A) Proteomic analysis identified 12 proteins associated with the asiatic acid pretreatment in the hippocampal synaptosomes of rats with KA-induced seizures. Global view of the protein spots on the two-dimensional gels. Protein spots with meaningful changes in intensity are labeled with Arabic numerals. (B) Western blot showing the expression levels of lipoamide dehydrogenase, GLUD1 (glutamate dehydrogenase 1), ATP5A (mitochondrial membrane ATP synthase), and SIRT3 (mitochondrial deacetylase sirtuin-3) in the hippocampus for each group. The relative protein levels were quantified. ${ }^{* *} p<0.01,{ }^{* * *} p<0.001$ (vs. control); $\#<0.001$ (asiatic acid + KA vs. KA); $n=5$ rats per group.

\subsection{Functional Network Analysis}

To delineate the relationships between the differentially expressed proteins elucidated by 2-DE and their significance in the mechanisms associated with the antiepileptic effect of asiatic acid, we used MetaCore ${ }^{\mathrm{TM}}$ software (Joseph, MI, USA) to predict the interactions among the targeted proteins revealed by the proteomic analysis. The network was generated using the shortest-path algorithm to map the interactions between the proteins. The highlighted lines represent specific, designated pathways, and the background lines represent the secondary, related biological pathways (Figure 8A). On the basis of this network, we found that treatment with asiatic acid affected inflammatory responses, ATP synthesis, and drug metabolism. As shown in Figure 8B, protein-protein interaction networks 
indicated that the proteins differentially expressed after treatment with asiatic acid were primarily involved in the following processes: drug metabolic process $\left(p=1.03 \times 10^{-9}\right)$, purine ribonucleotide metabolic process $\left(p=3.62 \times 10^{-9}\right)$, tricarboxylic acid metabolic process $\left(p=8.62 \times 10^{-8}\right)$, and ATP metabolic process $\left(p=9.28 \times 10^{-8}\right)$.

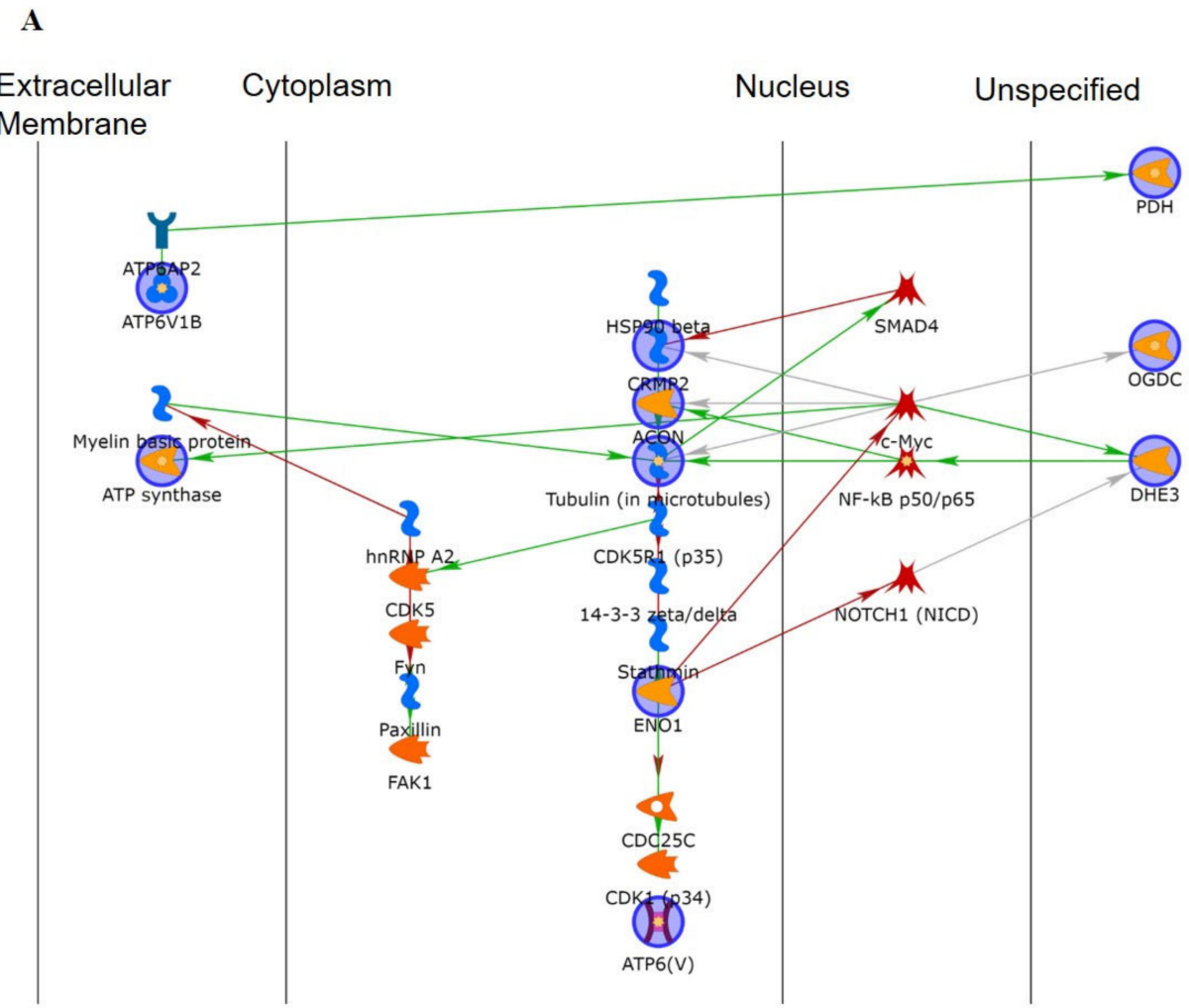

B

\begin{tabular}{|c|c|c|c|c|}
\hline$\checkmark$ & Biological Process (Gene Ontology) & & & \\
\hline G0-term & description & count in network & strength & $\triangle$ false discovery rate \\
\hline G0:0017144 & drug metabolic process & 8 of 324 & 1.64 & $1.03 \mathrm{e}-09$ \\
\hline GO:0009150 & purine ribonucleotide metabolic process & 7 of 223 & 1.74 & $3.62 \mathrm{e}-09$ \\
\hline GO:0044281 & small molecule metabolic process & 9 of 933 & 1.23 & $1.06 \mathrm{e}-08$ \\
\hline GO:0072350 & tricarboxylic acid metabolic process & 4 of 28 & 2.4 & $8.60 \mathrm{e}-08$ \\
\hline GO:0046034 & ATP metabolic process & 5 of 104 & 1.93 & $9.26 \mathrm{e}-08$ \\
\hline G0:0009152 & purine ribonucleotide biosynthetic process & 5 of 108 & 1.91 & $1.04 \mathrm{e}-07$ \\
\hline GO:0009205 & purine ribonucleoside triphosphate metabolic process & 5 of 120 & 1.86 & $1.30 \mathrm{e}-07$ \\
\hline GO:0009167 & purine ribonucleoside monophosphate metabolic process & 5 of 129 & 1.83 & $1.60 \mathrm{e}-07$ \\
\hline GO:0009987 & cellular process & 13 of 6022 & 0.58 & $4.76 \mathrm{e}-07$ \\
\hline G0:0006091 & generation of precursor metabolites and energy & 5 of 191 & 1.66 & $7.99 \mathrm{e}-07$ \\
\hline
\end{tabular}

Figure 8. (A) Biological network analyses of the differentially expressed proteins using MetaCore ${ }^{\mathrm{TM}}$ mapping tools. The nodes represent proteins and the lines between the nodes indicate direct proteinprotein interactions. The various proteins on this map are indicated by different symbols representing the functional class of the proteins. (B) The top-ranked pathways from the GeneGo MetaCore ${ }^{\mathrm{TM}}$ pathway analysis. The pathways were ranked according to the $p$ values. Color nodes: query proteins and first shell of interactors.

\section{Discussion}

Cognitive impairment is frequently observed in patients with epilepsy. Current AEDs only help with seizures and do not improve cognitive impairment $[4,6]$. Therefore, natural therapeutic agents that can not only treat epilepsy but also improve cognitive impairment must be developed $[22,23,44,45]$. The findings of the present study indicated that asiatic acid is a novel therapeutic intervention that can ameliorate seizures and associated memory impairment. In the present study, we found that asiatic acid administered before the induction of seizures by KA exhibited anti-seizure activity, improved cognitive function, 
attenuated neuronal damage, and restored synaptic protein levels and mitochondrial function.

Systemic administration of KA in animals has been widely used as an experimental model for the investigation of epilepsy [26]. Similar to the findings of previous studies $[23,46,47]$, the results of the present study indicated that rats treated with KA developed seizures and memory impairment. Pretreatment with asiatic acid (10 or $50 \mathrm{mg} / \mathrm{kg}$, i.p.) delayed the onset of seizure and reduced the severity of the seizure. This finding is in line with that reported by Wang et al., who revealed that $20-40 \mathrm{mg} / \mathrm{kg}$ asiatic acid exhibited anticonvulsant activity in a mouse model of KA-induced seizure [15]. In our study, pretreatment with asiatic acid improved memory impairment in rats with KA-induced seizure, indicating the effectiveness of this natural compound in epilepsy-associated cognitive impairment. Our finding is in agreement with those of previous studies that have reported that asiatic acid improved cognitive function in numerous animal models $[10,11,16,48]$.

Elucidating the possible mechanisms underlying the cognitive improvement by asiatic acid in KA-treated rats is critical. Numerous studies have indicated that neuronal loss in the hippocampus might be a consequence and a cause of cognitive deficits $[37,49,50]$. In the present study, KA treatment in rats caused significant neuronal death or degeneration in the CA1 and CA3 regions of the hippocampus; this finding is consistent with previous reports [21,22,25]. However, pretreatment with asiatic acid markedly attenuated neuronal loss and degeneration, indicating that asiatic acid protected hippocampal neurons against neurotoxicity in rats with KA-induced seizures. In addition, KA treatment results in neuronal damage or death, with associated increased levels of calpains, which are ubiquitously expressed calcium-activated proteases [39,51]. Calpain inhibition has been demonstrated to improve neuronal function and limit neuronal damage in several excitotoxic brain injuries $[38,40,44]$. In the current study, we observed that KA treatment increased the level of calpains and reduced the level of calpastatin, a calpain inhibitor, in the hippocampus. These KA-induced alterations were restored by pretreatment with asiatic acid, suggesting that asiatic acid treatment inhibited calpain activation. Moreover, we observed that KA reduced the levels of active AKT, a well-known cell survival pathway, in the hippocampus, which is consistent with the findings of previous studies [41,52]; however, pretreatment with asiatic acid restored the AKT level. Consistent with our findings, previous studies have reported that asiatic acid protects against neuronal damage by increasing AKT activation $[14,53]$. Thus, we speculate that asiatic acid increased AKT activation and inhibited calpain activation to significantly control neuronal death and protect neuronal cells, thus maintaining cognitive function in rats with KA-induced seizure.

A synaptic decline and plasticity deficiency have been implicated in KA-elicited cognitive impairment $[23,43,47]$. In the current study, KA treatment in rats reduced the levels of synapse-associated proteins, including presynaptic proteins (synaptobrevin, synapsin-1, and SNAP-25) and the postsynaptic protein PSD-95, and pretreatment with asiatic acid reversed such alterations. These proteins play a crucial regulatory role in the synaptic structure and transmission [54,55]. Particularly, synaptobrevin, synapsin-1, and SNAP-25 are synaptic vesicle-associated proteins that regulate the release of neurotransmitters. Decreases in these proteins and consequent decreases in available synaptic vesicles have been reported to be involved in cognitive dysfunction [56,57]. Therefore, asiatic acid might exert preventive effects against KA-induced cognitive impairment by maintaining the levels of synaptic proteins and vesicles in the hippocampus. This hypothesis is supported by the ultrastructure images of hippocampal synaptosomes, which indicates that pretreatment with asiatic acid restored synaptic vesicles reduced by KA administration. However, how asiatic acid restores the levels of synaptic proteins and vesicles to normal levels in KA-treated rats remains unclear. Calpain activation causes the proteolytic degradation of axonal proteins that play crucial roles in the regulation of neuronal activity [58]. Because asiatic acid inhibited the KA-induced increase in calpain expression in the hippocampus in our study, we speculate that asiatic acid could inhibit the calpain-mediated cleavage of synaptic pro- 
teins and consequently preserve synaptic proteins and vesicles in the hippocampus, thus contributing to the improvement of cognitive function of rats with KA-induced seizure.

Adequate energy supply by mitochondria in the brain is essential for neuronal function and survival. Deteriorated mitochondrial function and a consequent decrease in ATP production have been implicated in KA-induced neuronal damage and cognitive deficits [59-61]. In the present study, we observed significant mitochondrial ultrastructural damage in the hippocampal synaptosomes of KA-treated rats with seizure; however, pretreatment with asiatic acid prevented such ultrastructural damage. Furthermore, the findings of the proteomic analysis of hippocampal synaptosomes revealed 12 proteins associated with the effect of asiatic acid, particularly its effects on the mitochondrial proteins related to energy generation. Consistent with the results of the proteomics analysis, the levels of presynaptic mitochondrial proteins, namely lipoamide dehydrogenase, GLUD1, ATP synthase, and SIRT3, were significantly upregulated by pretreatment with asiatic acid. Moreover, our functional network analysis results revealed a relationship between asiatic acid and metabolic processes, especially the ATP metabolic process. In fact, energy is crucial for the brain to signal normally, while loss of energy can contribute to seizure generation by destabilizing membrane potentials and signaling in the chronic epileptic brain $[62,63]$. Furthermore, it has been shown that presynaptic mitochondria affect the magnitude of synaptic vesicle exocytosis, primarily through ATP synthesis [64]. Thus, we speculated that asiatic acid might increase synaptic vesicle exocytosis by alleviating KA-induced presynaptic mitochondrial damage and increasing ATP production in hippocampal neurons, which may be crucial to maintain synaptic function and prevent cognitive deficits. However, the details regarding the mechanism of asiatic acid's modulation of presynaptic mitochondrial bioenergetics were not elucidated in this study, and that should be investigated further.

Numerous studies have highlighted the cognitive improvement of asiatic acid $[10,11,16,48]$. Although the mechanism by which asiatic acid exhibits this beneficial effect is still under investigation, maintained anti-oxidative activity, suppressed neuroinflammation, increased acetylcholine synthesis, and promoted neurogenesis have been proposed [65]. In the present study, we did not examine the anti-inflammatory effect of asiatic acid in KA-injected rats. However, inflammatory responses, such as glia activation and inflammatory cytokine production, has been described in human epilepsy and in experimental models of epilepsy [66,67]. Thus, the possible involvement of suppressing inflammatory processes in the neuroprotective effect of asiatic acid observed in the present study should be considered.

KA causes excessive glutamate release and consequent glutamate receptor overstimulation, resulting in $\mathrm{Ca}^{2+}$ elevation, decreased AKT activation, and increased calpain activation. Decreased AKT or increased calpain activity results in the proteolytic degradation of synaptic proteins and mitochondrial damage and eventually neuronal damage and death, which may contribute to cognitive deficits $[40,47,52,58,61]$. Our results, together with the inhibition of glutamate release by asiatic acid [36], suggest asiatic acid may exert preventive effects against cognitive deficits in rats with KA-induced seizures through inhibiting glutamate release to increase AKT activation, inhibit calpain activation, and preserve synaptic and mitochondrial function (Figure 9).

The limitation of this study is that we do not know how much asiatic acid actually enters the brain. It has been reported that the therapeutic efficacy of asiatic acid is restricted due to its poor solubility and low penetrability into the brain [68]. Since brain permeability is a crucial factor for a drug to exhibit therapeutic effects at a target site, further study is warranted to elucidate the penetrability of asiatic acid in an in vivo, KA-induced cognitivedeficit model. However, it is known that in vivo animal models, while extremely useful in unravelling the mechanisms of human physiology, have limited capacity to mimic the complex and dynamic microenvironment of the human organs. To overcome these limitations, several 3-dimensional (3D) microfluidic and BBB on-a-chip and brain microvessel models have been developed. These models, which are capable of self-organization and functionality similar to the tissue of origin, can provide an alternative for drug analysis and 
development [69]. Although a successful result was achieved in this study, more studies are needed to assess whether asiatic acid treatment in humans is feasible.

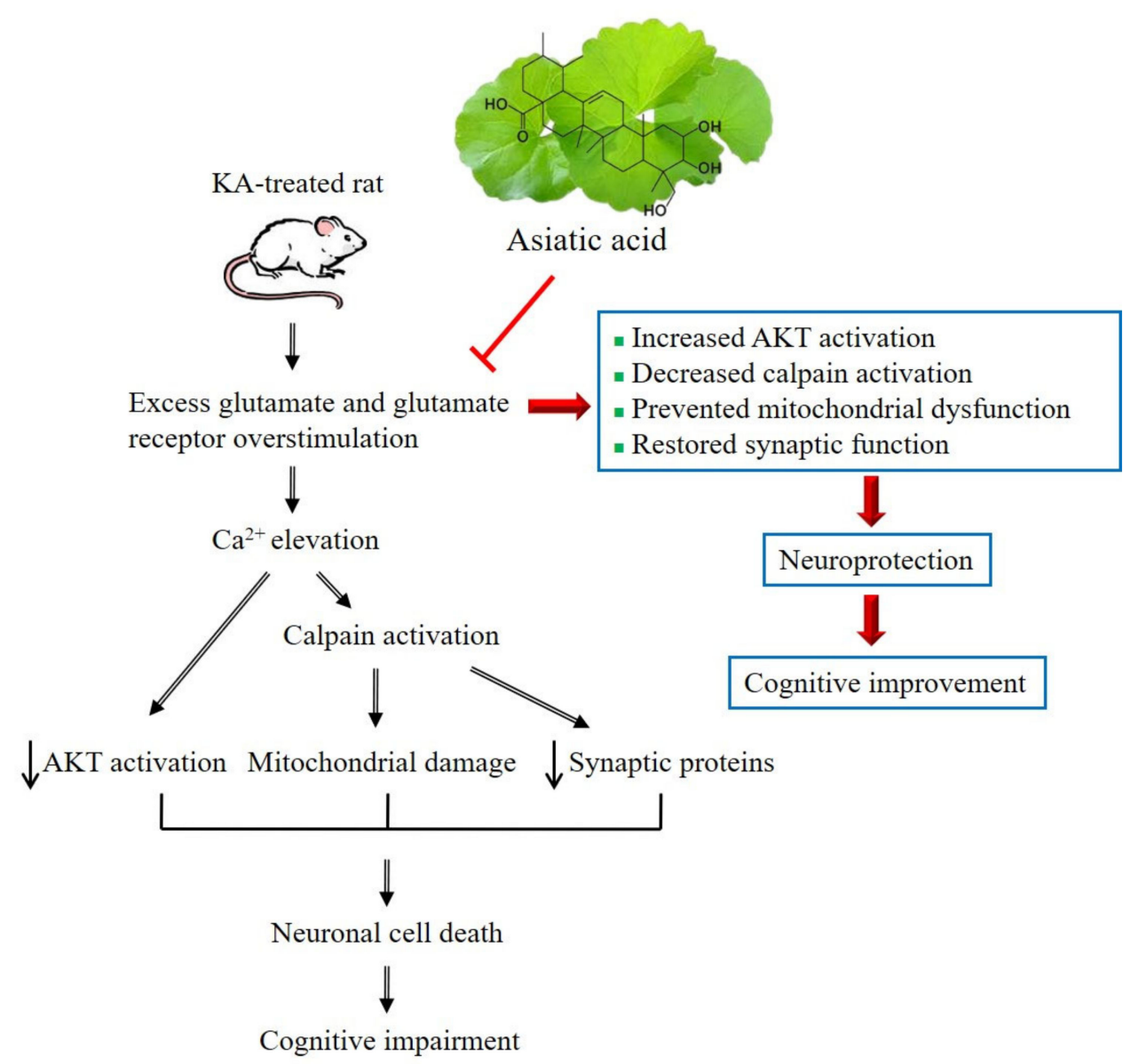

Figure 9. The proposed possible mechanisms underlying the cognitive improvement by asiatic acid in rats with KA-induced seizures. KA causes excessive glutamate release and consequent glutamate receptor overstimulation, resulting in $\mathrm{Ca}^{2+}$ elevation, decreased AKT activation, increased calpain activation, decreased synaptic proteins, mitochondrial damage, and eventually neuronal damage and death, which may contribute to cognitive deficits. Asiatic acid, through inhibiting glutamate release, can effectively inhibit calpain activation, increase AKT activation, and preserve synaptic and mitochondrial function, thus contributing to the improvement of the cognitive dysfunction of rats with KA-induced seizures.

\section{Conclusions}

Pretreatment with asiatic acid abrogates KA-induced pathophysiological events, such as neuronal cell death, decreased synaptic protein levels, and mitochondrial dysfunction in the hippocampus; these effects may at least partly contribute to the improvement of cognitive dysfunction. Therefore, asiatic acid may be a beneficial natural product for the treatment of epilepsy and associated cognitive deficits.

Author Contributions: Conceptualization, C.-W.L. and T.-Y.L.; data curation, T.-L.P., P.-W.W. and K.-M.C.; formal analysis, C.-W.L., T.-Y.L., T.-L.P. and P.-W.W.; funding acquisition, C.-W.L. and T.-Y.L.; investigation, C.-W.L., T.-Y.L. and S.-J.W.; project administration, M.-Y.L.; resources, T.-L.P., P.-W.W. and K.-M.C.; supervision, S.-J.W.; writing-original draft, S.-J.W.; writing-review and editing, M.-Y.L. and S.-J.W. All authors have read and agreed to the published version of the manuscript.

Funding: This work was supported by Ministry of Science and Technology (MOST 106-2320-B-030002 MY3) and Far Eastern Memorial Hospital (FEMH-2019-C-011; FEMH-2019-C-021), Taiwan. 
Institutional Review Board Statement: Ethical approval was granted by the Fu Jen Catholic University (No. AE10561, 03 May 2017) and, therefore, experiments were performed in accordance with the ethical standards laid out by the IACUC.

Informed Consent Statement: Not applicable.

Data Availability Statement: Not applicable.

Conflicts of Interest: The authors declare there are no conflict of interest.

\section{References}

1. Moshé, S.L.; Perucca, E.; Ryvlin, P.; Tomson, T. Epilepsy: New advances. Lancet 2015, 385, 884-898. [CrossRef]

2. Elger, C.E.; Helmstaedter, C.; Kurthen, M. Chronic epilepsy and cognition. Lancet Neurol. 2004, 3, 663-672. [CrossRef]

3. Lin, J.J.; Mula, M.; Hermann, B.P. Uncovering the neurobehavioural comorbidities of epilepsy over the lifespan. Lancet 2012, 380, 1180-1192. [CrossRef]

4. Witt, J.A.; Helmstaedter, C. Cognition in epilepsy: Current clinical issues of interest. Curr. Opin. Neurol. 2017, 30, 174-179. [CrossRef] [PubMed]

5. Ortinski, P.; Meador, K.J. Cognitive side effects of antiepileptic drugs. Epilepsy Behav. 2004, 5 (Suppl. 1), S60-S65. [CrossRef]

6. Santulli, L.; Coppola, A.; Balestrini, S.; Striano, S. The challenges of treating epilepsy with 25 antiepileptic drugs. Pharmacol. Res. 2016, 107, 211-219. [CrossRef]

7. Zhao, Z.; He, X.; Ma, C.; Wu, S.; Cuan, Y.; Sun, Y.; Bai, Y.; Huang, L.; Chen, X.; Gao, T.; et al. Excavating anticonvulsant compounds from prescriptions of traditional chinese medicine in the treatment of epilepsy. Am. J. Chin. Med. 2018, 46, 707-737. [CrossRef]

8. Auditeau, E.; Chassagne, F.; Bourdy, G.; Bounlu, M.; Jost, J.; Luna, J.; Ratsimbazafy, V.; Preux, P.M.; Boumediene, F. Herbal medicine for epilepsy seizures in Asia, Africa and Latin America: A systematic review. J. Ethnopharmacol. 2019, 234, 119-153. [CrossRef]

9. Hashim, P.; Sidek, H.; Helan, M.H.; Sabery, A.; Palanisamy, U.D.; Ilham, M. Triterpene composition and bioactivities of Centella asiatica. Molecules 2011, 16, 1310-1322. [CrossRef]

10. Xu, M.F.; Xiong, Y.Y.; Liu, J.K.; Qian, J.J.; Zhu, L.; Gao, J. Asiatic acid, a pentacyclic triterpene in Centella asiatica, attenuates glutamate-induced cognitive deficits in mice and apoptosis in SH-SY5Y cells. Acta. Pharmacol. Sin. 2012, 33, 578-587. [CrossRef]

11. Sirichoat, A.; Chaijaroonkhanarak, W.; Prachaney, P.; Pannangrong, W.; Leksomboon, R.; Chaichun, A.; Wigmore, P.; Welbat, J.U. Effects of asiatic acid on spatial working memory and cell proliferation in the adult rat hippocampus. Nutrients 2015, 7, 8413-8423. [CrossRef]

12. Jiang, W.; Li, M.; He, F.; Bian, Z.; He, Q.; Wang, X.; Yao, W.; Zhu, L. Neuroprotective effect of asiatic acid against spinal cord injury in rats. Life Sci. 2016, 157, 45-51. [CrossRef]

13. Nataraj, J.; Manivasagam, T.; Justin Thenmozhi, A.; Essa, M.M. Neuroprotective effect of asiatic acid on rotenone-induced mitochondrial dysfunction and oxidative stress-mediated apoptosis in differentiated SH-SYS5Y cells. Nutr. Neurosci. 2017, 20, 351-359. [CrossRef] [PubMed]

14. Nataraj, J.; Manivasagam, T.; Justin Thenmozhi, A.; Essa, M.M. Neurotrophic effect of asiatic acid, a triterpene of Centella asiatica against chronic 1-methyl 4-phenyl 1, 2, 3, 6-tetrahydropyridine hydrochloride/probenecid mouse model of Parkinson's disease: The role of MAPK, PI3K-Akt-GSK3 $\beta$ and mTOR signalling pathways. Neurochem. Res. 2017, 42, 1354-1365. [CrossRef]

15. Wang, Z.H.; Mong, M.C.; Yang, Y.C.; Yin, M.C. Asiatic acid and maslinic acid attenuated kainic acid-induced seizure through decreasing hippocampal inflammatory and oxidative stress. Epilepsy Res. 2018, 139, 28-34. [CrossRef] [PubMed]

16. Loganathan, C.; Thayumanavan, P. Asiatic acid prevents the quinolinic acid-induced oxidative stress and cognitive impairment. Metab. Brain Dis. 2018, 33, 151-159. [CrossRef]

17. Ahmad Rather, M.; Justin-Thenmozhi, A.; Manivasagam, T.; Saravanababu, C.; Guillemin, G.J.; Essa, M.M. Asiatic acid attenuated aluminum chloride-induced tau pathology, oxidative stress and apoptosis via AKT/GSK-3 $\beta$ signaling pathway in wistar rats. Neurotox. Res. 2019, 35, 955-968. [CrossRef] [PubMed]

18. Lu, C.W.; Lin, T.Y.; Wang, S.J.; Huang, S.K. Asiatic acid, an active substance of Centella asiatica, presynaptically depresses glutamate release in the rat hippocampus. Eur. J. Pharmacol. 2019, 865, 172781. [CrossRef] [PubMed]

19. Krishnamurthy, R.G.; Senut, M.C.; Zemke, D.; Min, J.; Frenkel, M.B.; Greenberg, E.J.; Yu, S.W.; Ahn, N.; Goudreau, J.; Kassab, M.; et al. Asiatic acid, a pentacyclic triterpene from Centella asiatica, is neuroprotective in a mouse model of focal cerebral ischemia. J. Neurosci. Res. 2009, 87, 2541-2550. [CrossRef]

20. Raval, N.; Mistry, T.; Acharya, N.; Acharya, S. Development of glutathione-conjugated asiatic acid-loaded bovine serum albumin nanoparticles for brain-targeted drug delivery. J. Pharm. Pharmacol. 2015, 67, 1503-1511. [CrossRef]

21. Kim, S.; Jung, U.J.; Oh, Y.S.; Jeon, M.T.; Kim, H.J.; Shin, W.H.; Hong, J.; Kim, S.R. Beneficial effects of silibinin against kainic acid-induced neurotoxicity in the hippocampus in vivo. Exp. Neurobiol. 2017, 26, 266-277. [CrossRef] [PubMed]

22. Hashemi, P.; FahanikBabaei, J.; Vazifekhah, S.; Nikbakht, F. Evaluation of the neuroprotective, anticonvulsant, and cognitionimprovement effects of apigenin in temporal lobe epilepsy: Involvement of the mitochondrial apoptotic pathway. Iran J. Basic Med. Sci. 2019, 22, 752-758. [CrossRef] 
23. Zhu, X.; Liu, J.; Huang, S.; Zhu, W.; Wang, Y.; Chen, O.; Xue, J. Neuroprotective effects of isoliquiritigenin against cognitive impairment via suppression of synaptic dysfunction, neuronal injury, and neuroinflammation in rats with kainic acid-induced seizures. Int. Immunopharmacol. 2019, 72, 358-366. [CrossRef] [PubMed]

24. Nadler, J.V. Minireview. Kainic acid as a tool for the study of temporal lobe epilepsy. Life Sci. 1981, 29, 2031-2042. [CrossRef]

25. Ben-Ari, Y. Limbic seizure and brain damage produced by kainic acid: Mechanisms and relevance to human temporal lobe epilepsy. Neuroscience 1985, 14, 375-403. [CrossRef]

26. Lévesque, M.; Avoli, M. The kainic acid model of temporal lobe epilepsy. NeurosciBiobehavRev. 2013, 37, 2887-2899. [CrossRef]

27. Racine, R.J. Modification of seizure activity by electrical stimulation. II. Motor seizure. Electroencephalogr. Clin. Neurophysiol. 1972, 32, 281-294. [CrossRef]

28. Friedman, L.K.; Pellegrini-Giampietro, D.E.; Sperber, E.F.; Bennett, M.V.; Moshé, S.L.; Zukin, R.S. Kainate-induced status epilepticus alters glutamate and GABAA receptor gene expression in adult rat hippocampus: An in situ hybridization study. $J$. Neurosci. 1994, 14, 2697-2707. [CrossRef]

29. Chang, Y.; Lu, C.W.; Chen, Y.J.; Lin, T.Y.; Huang, S.K.; Wang, S.J. Astaxanthin protects against kainic acid-induced seizures and pathological consequences. Neurochem. Int. 2018, 116, 85-94. [CrossRef] [PubMed]

30. Lu, C.W.; Lin, T.Y.; Chiu, K.M.; Lee, M.Y.; Huang, J.H.; Wang, S.J. Silymarin inhibits glutamate release and prevents against kainic acid-induced excitotoxic injury in rats. Biomedicines 2020, 8. [CrossRef]

31. Lin, T.Y.; Lu, C.W.; Wang, S.J. Luteolin protects the hippocampus against neuron impairments induced by kainic acid in rats. Neurotoxicology 2016, 55, 48-57. [CrossRef]

32. Lin, T.Y.; Lu, C.W.; Wu, C.C.; Huang, S.K.; Wang, S.J. Palmitoylethanolamide inhibits glutamate release in rat cerebrocortical nerve terminals. Int. J. Mol. Sci. 2015, 16, 5555-5571. [CrossRef]

33. Lin, T.Y.; Wang, P.W.; Huang, C.H.; Yang, P.M.; Pan, T.L. Characterizing the relapse potential in different luminal subtypes of breast cancers with functional proteomics. Int. J. Mol. Sci. 2020, 21, 6077. [CrossRef] [PubMed]

34. Wang, P.W.; Hung, Y.C.; Lin, T.Y.; Fang, J.Y.; Yang, P.M.; Chen, M.H.; Pan, T.L. Comparison of the biological impact of UVA and UVB upon the skin with functional proteomics and immunohistochemistry. Antioxidants 2019, 8, 569. [CrossRef]

35. Hung, Y.C.; Wang, P.W.; Lin, T.Y.; Yang, P.M.; You, J.S.; Pan, T.L. Functional redox proteomics reveal that Salvia miltiorrhiza aqueous extract alleviates adriamycin-induced cardiomyopathy via inhibiting ROS-dependent apoptosis. Oxid. Med. Cell Longev. 2020, 2020, 5136934. [CrossRef]

36. Lu, C.W.; Lin, T.Y.; Huang, S.K.; Wang, S.J. Echinacoside Inhibits Glutamate Release by Suppressing Voltage-Dependent Ca(2+) Entry and Protein Kinase C in Rat Cerebrocortical Nerve Terminals. Int. J. Mol. Sci. 2016, 17, 1006. [CrossRef]

37. Maia, G.H.; Quesado, J.L.; Soares, J.I.; do Carmo, J.M.; Andrade, P.A.; Andrade, J.P.; Lukoyanov, N.V. Loss of hippocampal neurons after kainate treatment correlates with behavioral deficits. PLoS ONE 2014, 9, e84722. [CrossRef] [PubMed]

38. Nam, H.Y.; Na, E.J.; Lee, E.; Kwon, Y.; Kim, H.J. Antiepileptic and neuroprotective effects of oleamide in rat striatum on kainate-induced behavioral seizure and excitotoxic damage via calpain inhibition. Front. Pharmacol. 2017, 8, 817. [CrossRef] [PubMed]

39. Lam, P.M.; González, M.I. Calpain activation and neuronal death during early epileptogenesis. Neurobiol. Dis. 2019, 124, 141-151. [CrossRef] [PubMed]

40. Machado, V.M.; Lourenço, A.S.; Florindo, C.; Fernandes, R.; Carvalho, C.M.; Araújo, I.M. Calpastatin overexpression preserves cognitive function following seizures, while maintaining post-injury neurogenesis. Front. Mol. Neurosci. 2017, 10, 60. [CrossRef] [PubMed]

41. Lee, S.H.; Chun, W.; Kong, P.J.; Han, J.A.; Cho, B.P.; Kwon, O.Y.; Lee, H.J.; Kim, S.S. Sustained activation of Akt by melatonin contributes to the protection against kainic acid-induced neuronal death in hippocampus. J. Pineal Res. 2006, 40, 79-85. [CrossRef]

42. Piermartiri, T.C.; Vandresen-Filho, S.; de Araújo Herculano, B.; Martins, W.C.; Dal'agnolo, D.; Stroeh, E.; Carqueja, C.L.; Boeck, C.R.; Tasca, C.I. Atorvastatin prevents hippocampal cell death due to quinolinic acid-induced seizures in mice by increasing Akt phosphorylation and glutamate uptake. Neurotox. Res. 2009, 16, 106-115. [CrossRef]

43. Zhang, F.X.; Sun, Q.J.; Zheng, X.Y.; Lin, Y.T.; Shang, W.; Wang, A.H.; Duan, R.S.; Chi, Z.F. Abnormal expression of synaptophysin, SNAP-25, and synaptotagmin 1 in the hippocampus of kainic acid-exposed rats with behavioral deficits. Cell Mol. Neurobiol. 2014, 34, 813-824. [CrossRef]

44. Shi, C.; Zeng, J.; Li, Z.; Chen, Q.; Hang, W.; Xia, L.; Wu, Y.; Chen, J.; Shi, A. Melatonin mitigates kainic acid-induced neuronal tau hyperphosphorylation and memory deficits through alleviating ER stress. Front. Mol. Neurosci. 2018, 11, 5. [CrossRef] [PubMed]

45. Kundap, U.P.; Paudel, Y.N.; Kumari, Y.; Othman, I.; Shaikh, M.F. Embelin prevents seizure and associated cognitive impairments in a pentylenetetrazole-induced kindling zebrafish model. Front. Pharmacol. 2019, 10, 315. [CrossRef] [PubMed]

46. Jia, C.; Han, S.; Wei, L.; Dang, X.; Niu, Q.; Chen, M.; Cao, B.; Liu, Y.; Jiao, H. Protective effect of compound Danshen (Salvia miltiorrhiza) dripping pills alone and in combination with carbamazepine on kainic acid-induced temporal lobe epilepsy and cognitive impairment in rats. Pharm. Biol. 2018, 56, 217-224. [CrossRef] [PubMed]

47. Ye, Q.; Zeng, C.; Luo, C.; Wu, Y. Ferrostatin-1 mitigates cognitive impairment of epileptic rats by inhibiting P38 MAPK activation. Epilepsy Behav. 2020, 103, 106670. [CrossRef]

48. Kim, S.R.; Koo, K.A.; Lee, M.K.; Park, H.G.; Jew, S.S.; Cha, K.H.; Kim, Y.C. Asiatic acid derivatives enhance cognitive performance partly by improving acetylcholine synthesis. J. Pharm. Pharmacol. 2004, 56, 1275-1282. [CrossRef] [PubMed]

49. Aiyer, R.S.; Nath, J.R. Mechanisms of memory deficit in temporal lobe epilepsy. NZMSJ 2011, 22, 6052-6061. 
50. Titiz, A.S.; Mahoney, J.M.; Testorf, M.E.; Holmes, G.L.; Scott, R.C. Cognitive impairment in temporal lobe epilepsy: Role of online and offline processing of single cell information. Hippocampus 2014, 24, 1129-1145. [CrossRef]

51. Xue, F.; Shi, C.; Chen, Q.; Hang, W.; Xia, L.; Wu, Y.; Tao, S.Z.; Zhou, J.; Shi, A.; Chen, J. Melatonin mediates protective effects against kainic acid-induced neuronal death through safeguarding ER stress and mitochondrial disturbance. Front. Mol. Neurosci. 2017, 10, 49. [CrossRef] [PubMed]

52. Zhang, J.; Han, Y.; Zhao, Y.; Li, Q.; Jin, H.; Qin, J. Inhibition of TRIB3 protects against neurotoxic injury induced by kainic acid in rats. Front. Pharmacol. 2019, 10, 585. [CrossRef] [PubMed]

53. Cheng, W.; Chen, W.; Wang, P.; Chu, J. Asiatic acid protects differentiated PC12 cells from A $\beta(25-35)$-induced apoptosis and tau hyperphosphorylation via regulating PI3K/Akt/GSK-3 $\beta$ signaling. Life Sci. 2018, 208, 96-101. [CrossRef] [PubMed]

54. Martin, S.J.; Grimwood, P.D.; Morris, R.G. Synaptic plasticity and memory: An evaluation of the hypothesis. AnnuRev. Neurosci. 2000, 23, 649-711. [CrossRef]

55. Antonova, I.; Arancio, O.; Trillat, A.C.; Wang, H.G.; Zablow, L.; Udo, H.; Kandel, E.R.; Hawkins, R.D. Rapid increase in clusters of presynaptic proteins at onset of long-lasting potentiation. Science 2001, 294, 1547-1550. [CrossRef] [PubMed]

56. Lynch, M.A.; Voss, K.L.; Rodriguez, J.; Bliss, T.V. Increase in synaptic vesicle proteins accompanies long-term potentiation in the dentate gyrus. Neuroscience 1994, 60, 1-5. [CrossRef]

57. Mullany, P.; Lynch, M.A. Changes in protein synthesis and synthesis of the synaptic vesicle protein, synaptophysin, in entorhinal cortex following induction of long-term potentiation in dentate gyrus: An age-related study in the rat. Neuropharmacology 1997, 36, 973-980. [CrossRef]

58. Saatman, K.E.; Bozyczko-Coyne, D.; Marcy, V.; Siman, R.; McIntosh, T.K. Prolonged calpain-mediated spectrin breakdown occurs regionally following experimental brain injury in the rat. J. Neuropathol. Exp. Neurol. 1996, 55, 850-860. [CrossRef]

59. Lai, Y.C.; Baker, J.S.; Donti, T.; Graham, B.H.; Craigen, W.J.; Anderson, A.E. Mitochondrial Dysfunction Mediated by Poly(ADPRibose) Polymerase-1 Activation Contributes to Hippocampal Neuronal Damage Following Status Epilepticus. Int. J. Mol. Sci. 2017, 18, 1502. [CrossRef]

60. Gano, L.B.; Liang, L.P.; Ryan, K.; Michel, C.R.; Gomez, J.; Vassilopoulos, A.; Reisdorph, N.; Fritz, K.S.; Patel, M. Altered mitochondrial acetylation profiles in a kainic acid model of temporal lobe epilepsy. Free Radic. Biol. Med. 2018, 123, 116-124. [CrossRef]

61. Chuang, Y.C.; Chen, S.D.; Jou, S.B.; Lin, T.K.; Chen, S.F.; Chen, N.C.; Hsu, C.Y. Sirtuin 1 regulates mitochondrial biogenesis and provides an endogenous neuroprotective mechanism against seizure-induced neuronal cell death in the hippocampus following status epilepticus. Int. J. Mol. Sci. 2019, 20, 3588. [CrossRef] [PubMed]

62. Bordone, M.P.; Salman, M.M.; Titus, H.E.; Amini, E.; Andersen, J.V.; Chakraborti, B.; Diuba, A.V.; Dubouskaya, T.G.; Ehrke, E.; Espindola de Freitas, A.; et al. The energetic brain-A review from students to students. J. Neurochem. 2019, 151, 139-165. [CrossRef] [PubMed]

63. Cloix, J.F.; Hevor, T. Epilepsy, regulation of brain energy metabolism and neurotransmission. Curr. Med. Chem. 2009, 16, 841-853. [CrossRef]

64. Ivannikov, M.V.; Sugimori, M.; Llinás, R.R. Synaptic vesicle exocytosis in hippocampal synaptosomes correlates directly with total mitochondrial volume. J. Mol. Neurosci. 2013, 49, 223-230. [CrossRef]

65. Gray, N.E.; Alcazar, M.A.; Lak, P.; Wright, K.M.; Quinn, J.; Stevens, J.F.; Maier, C.S.; Soumyanath, A. Centella asiaticaPhytochemistry and mechanisms of neuroprotection and cognitive enhancement. Phytochem Rev. 2018, 17, 161-194. [CrossRef]

66. Binder, D.K.; Steinhauser, C. Functional changes in astroglial cells in epilepsy. Glia 2006, 54, 358-368. [CrossRef]

67. Verdugo, C.D.; Myren-Svelstad, S.; Aydin, E.; Hoeymissen, E.V.; Deneubourg, C.; Vanderhaeghe, S.; Vancraeynest, J.; Pelgrims, R.; Cosacak, M.I.; Muto, A.; et al. Glia-neuron interactions underlie state transitions to generalized seizures. Nat. Commun. 2019, 10, 3830. [CrossRef] [PubMed]

68. Yasurin, P.; Sriariyanun, M.; Phusantisampan, T. Review: The bioavailability activity of Centella asiatica, KMUTNB. Int. J. Appl. Sci. Technol. 2016, 9, 1-9. [CrossRef]

69. Salman, M.M.; Marsh, G.; Kusters, I.; Delincé, M.; Di Caprio, G.; Upadhyayula, S.; de Nola, G.; Hunt, R.; Ohashi, K.G.; Gray, T.; et al. Design and validation of a human brain endothelial microvessel-on-a-chip open microfluidic model enabling advanced optical imaging. Front. Bioeng. Biotechnol. 2020, 8, 573775. [CrossRef] 